\title{
Strong Circularly Polarized Luminescence of an Octahedral Chromium(III) Complex
}

Received 00th January 20xx, Accepted 00th January 20xx DOI: $10.1039 / \times 0 \times x 00000 x$
Carolin Dee, ${ }^{a}$ Francesco Zinna, ${ }^{b}$ Winald R. Kitzmann, ${ }^{c}$ Gennaro Pescitelli, ${ }^{b}$ Katja Heinze, ${ }^{* c}$ Lorenzo Di Bari*b and Michael Seitz*a
The chiral spin-flip luminophore $\left[\mathrm{Cr}(\mathrm{ddpd})_{2}\right]^{3+}$ can be resolved into enantiopure material by chiral HPLC. The corresponding enantiomers show very high luminescence dissymmetry factors of up to $\left|g_{\text {lum }}\right| \approx 0.093$ in circularly polarized luminescence (CPL) measurements for the "ruby-like" phosphorescence transition ${ }^{2} \mathrm{E} /{ }^{2} \mathrm{~T}_{1} \rightarrow{ }^{4} \mathrm{~A}_{2}$ in the near-IR region around $\lambda \approx 775 \mathrm{~nm}$.

The development of efficient luminophores capable of emitting "enantioenriched" light, i.e. the preferential emission of one form of either left- or right-circularly polarized luminescence (CPL), is a fascinating field in the photonic sciences due to many emerging applications (e.g. CPL bioanalytics, CP-OLEDs, etc.). ${ }^{1,2}$ Naturally, the observation of CPL activity in isolated molecules is only possible for chiral, non-racemic compounds, ideally in enantiopure and configurationally stable systems. The extent of enantiomeric excess in the emitted, circularly polarized light is usually expressed as luminescence dissymmetry factor $g_{\text {lum }}$ given as:

$$
g_{\text {lum }}(\lambda)=2 \frac{I_{L}(\lambda)-I_{R}(\lambda)}{I_{L}(\lambda)+I_{R}(\lambda)} ; \quad\left[-2 \leq g_{\text {lum }} \leq+2\right]
$$

with $I_{L}$ and $I_{R}$ being the intensities of left- and right-circularly polarized light at a specific emission wavelength $\lambda$, respectively. For practical CPL applications, large values of $g_{\text {lum }}$ are desirable, as well as high general photoluminescence quantum efficiencies $\Phi_{\text {lum }}$ especially at the emissive transition chosen for CPL observation and sizeable molar extinction coefficients $\varepsilon$ at the excitation wavelength $\lambda_{\text {exc }}$. High values of glum are especially expected for luminescence bands which are electric dipole forbidden and magnetic dipole allowed. ${ }^{3}$

a. Institute of Inorganic Chemistry, University of Tübingen, Auf der Morgenstelle 18 72076 Tübingen, Germany.E-mail: michael.seitz@uni-tuebingen.de

b. Dipartimento di Chimica e Chimica Industriale, Università di Pisa, Via Moruzzi 13, 56124 Pisa, Italy. E-mail: lorenzo.dibari@unipi.it

c. Institute of Inorganic Chemistry and Analytical Chemistry, Johannes Gutenberg University of Mainz, Duesbergweg 10-14, 55128 Mainz, Germany. E-mail: katja.heinze@uni-mainz.de

Electronic Supplementary Information (ESI) available: Details of the chira resolution, configurational stability, assignment of absolute configurations, $C D$ spectroscopy, computational estimation of the racemization barriers. See DOI: $10.1039 / x 0 x \times 00000 x$
Therefore, while organic and most inorganic transition metal luminophores have a rich history in the photophysics of enantiopure compounds, the nature of the most prevalent luminescent transitions does not bode well for the achievement of high dissymmetry factors and typically, relatively small values of ca. $10^{-4}<g_{\text {lum }}<10^{-2}$ are the norm. ${ }^{1,4}$ On the other hand, the best candidates for the realization of sizeable $g_{\text {lum }}$ factors are enantiopure complexes with trivalent lanthanoid cations where $g_{\text {lum }}$ is routinely a few orders of magnitudes larger (ca. $10^{-2}<g_{\text {lum }}<1$ ) than in other systems ${ }^{2}$ and can reach values of up to 1.38 in solution. ${ }^{5}$ Despite the suitability of lanthanoids for the development of efficient CPL emitters, it is highly desirable to have alternatives based on other, more abundant elements. In addition, the most prevalent CPL-active transitions of lanthanoids (mostly for $\mathrm{Eu}^{3+}$ and $\mathrm{Tb}^{3+}$ ) do not cover various spectral ranges, for example the important near-IR wavelength region from approx. 700-900 $\mathrm{nm}$. One of the most promising avenues for the development of alternative CPL-emitters is based on the photophysics of chromium(III) complexes, best known for the optical properties (e.g. color, luminescence) of ruby. Especially the phosphorescent, spin-flip-transitions analogous to the R1- and R2-ruby laser lines $\left({ }^{2} \mathrm{E} /{ }^{2} \mathrm{~T}_{1} \rightarrow{ }^{4} \mathrm{~A}_{2}\right)$ have many properties that are reminiscent of the best $\mathrm{CPL}$-active lanthanoid transitions (excited and ground states in the weak coupling limit, strongly electric-dipole forbidden, magnetically allowed). ${ }^{6}$ Despite encouraging proof-of-concept CPL studies in the solid state and at low-temperature, previous work on $\mathrm{Cr}^{3+}{ }_{-} \mathrm{CPL}$ starting as early as 1967 was hampered by the fact that generally, molecular chromium(III) complexes only showed very low quantum efficiencies at room temperature in solution and the potential for realistic CPL-applications was therefore rather low. ${ }^{7}$ This situation has changed recently with the development of the molecular ruby $\left[\mathrm{Cr}(\mathrm{ddpd})_{2}\right]^{3+}$ (Figure 1$)^{8}$ which has extraordinarily high phosphorescence quantum yields $\Phi$ of up to $30 \%$ in deoxygenated solutions at room temperature, especially after reducing multiphonon quenching through deuteration of the ligands and the solvent (see Figure 1). In a seminal work in the area of CPL luminophores, Piguet et al. ${ }^{9}$ 


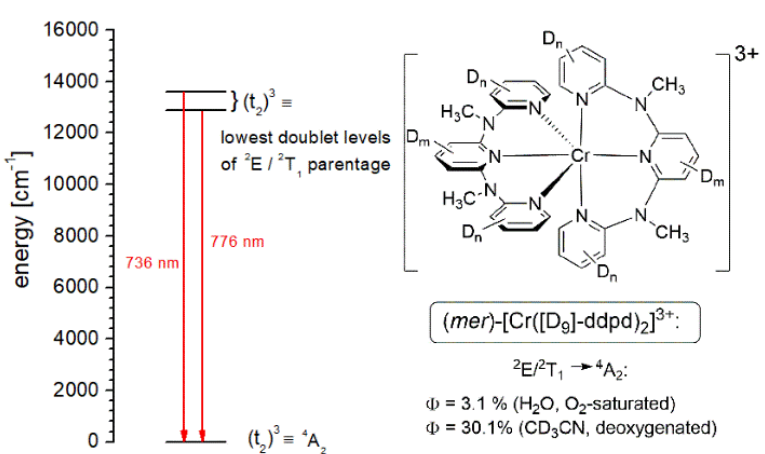

Figure 1. Energy level diagram for the metal-centered states in the chromium complex $\left[\mathrm{Cr}(\mathrm{ddpd})_{2}\right]^{3+}$ showing the "ruby-like" spin-flip emission ${ }^{2} \mathrm{E} /{ }^{2} \mathrm{~T}_{1} \rightarrow{ }^{4} \mathrm{~A}_{2}$ with very favorable general luminescence properties such as high quantum yields $\Phi$, especially in the deuterated version shown. ${ }^{8}$

could show recently that a similar, enantiopure chromium(III) complex is indeed capable of combining sizeable general phosphorescence quantum yields $(\Phi=5.2 \%$ in deoxygenated $\mathrm{H}_{2} \mathrm{O}$ at room temperature) with unprecedentedly high values for the luminescence dissymmetry factors of up to $\left|\mathrm{g}_{\text {lum }}\right|=0.2$. In this communication, we show that the successful luminophore $\left[\mathrm{Cr}(\mathrm{ddpd})_{2}\right]^{3+}$, which previously was employed in its racemic form, can also be resolved into enantiopure material and that the enantiomers exhibit very high glum values for a 3d-metal complex.

Despite its simplified depiction in Figure 1 , the complex $\left[\mathrm{Cr}(\mathrm{ddpd})_{2}\right]^{3+}$ is not achiral with $D_{2 d}$ symmetry as would be expected for a homoleptic, meridionally coordinated metal center with planar tridentate chelators such as tpy. Instead, the previously determined structure of racemic material in the solid state ${ }^{8 b}$ shows strongly twisted ddpd ligands with homochiral helicities ( $M, M$ or $P, P)$, which effectively lowers the local symmetry to $D_{2}$, making the complex chiral (Scheme 1). Since the chirality of the complexes only relies on the conformations of the rather flexible ddpd ligands, it was not clear at the outset if these presumably rather "soft" stereogenic elements would be suitable to endow the complex with enough configurational stability in order to be able to obtain pure enantiomers and to prevent their rapid racemization once resolved.

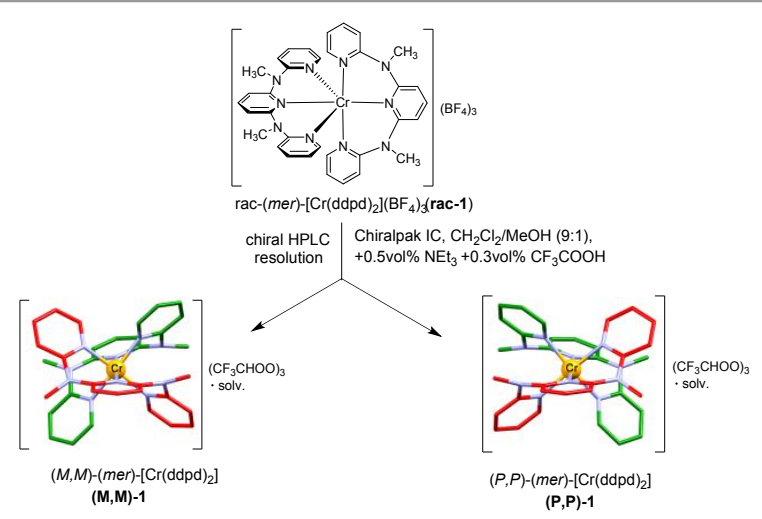

Scheme 1. Chiral resolution of the racemic, meridional chromium(III) complex $\left[\mathrm{Cr}(\mathrm{ddpd})_{2}\right]^{3+}$ into the $(M, M)$ - and $(P, P)$-enantiomers (schematic representations, red and green colors used for carbon atoms in different ddpd units in order to clarify the helicity of each ligand).

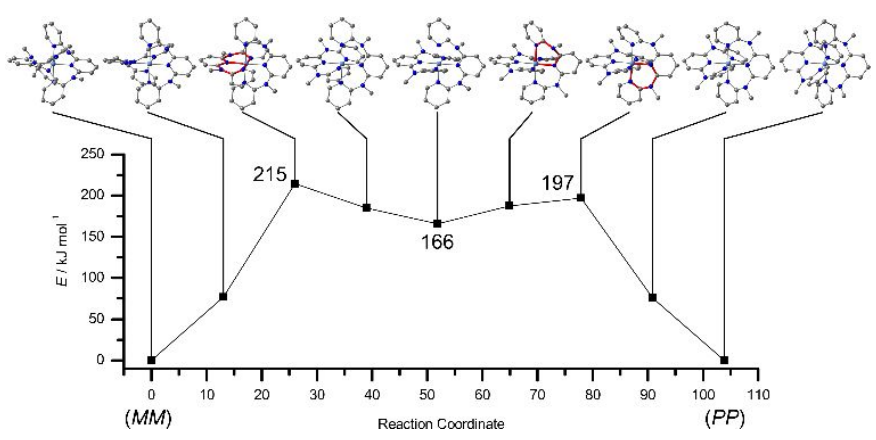

Figure 2. DFT calculations of the trajectory for the stepwise racemization of sixcoordinate $\left[\mathrm{Cr}(\mathrm{ddpd})_{2}\right]^{3+}$ (hydrogen atoms omitted; inverting chelate rings marked in red; see the ESI for details).

In order to evaluate this question, we performed DFT calculations along possible racemization trajectories (Figure 2, see ESI for details). The highest energy species was calculated at $215 \mathrm{~kJ} / \mathrm{mol}$ higher in energy than the ground state $\left(D_{2^{-}}\right.$ symmetric enantiomers). These results suggest that racemization of $(\mathbf{M}, \mathbf{M})-\mathbf{1}$ or $\mathbf{( P , P ) - 1}$ without a change in coordination number is rather unlikely and a dissociative or associative pathway might be followed instead (if racemization occurs at all). Pathways with 5- or 7-coordinate intermediates $\left[\mathrm{Cr}(\mathrm{ddpd})\left(\mathrm{k}^{2} \mathrm{~N}-\mathrm{ddpd}\right)\right]^{3+}$ or $\left[\mathrm{Cr}(\mathrm{ddpd})_{2}\left(\mathrm{H}_{2} \mathrm{O}\right)\right]^{3+}$ are either high in energy (calculated free dissociation enthalpy of $132 \mathrm{~kJ} / \mathrm{mol}$ ) or inaccessible $\left(\mathrm{H}_{2} \mathrm{O}\right.$ coordination to $\mathrm{Cr}$ proved unfeasible). This suggests considerable configurational stability of $\left[\mathrm{Cr}(\mathrm{ddpd})_{2}\right]^{3+}$. The practical resolution of the two enantiomers proved to be surprisingly difficult and to date we were only successful by employing chiral HPLC using highly optimized conditions (see ESI for details). The racemic material rac-1 clearly shows two peaks with a peak area ratio very close to 50:50 (Figure 3A) which, despite considerable efforts, could not be baselineseparated completely. For separations on a larger scale necessary for the spectroscopic work, it proved impossible to cleanly obtain the first fraction without contamination by the second fraction and consequently gave only an enantiomeric excess of $80 \%$. In contrast, sampling only the middle and tail portions of the second fraction provided enantiopure material ( $100 \%$ ee). Nevertheless, CD spectra of both fractions in deoxygenated $\mathrm{D}_{2} \mathrm{O}$ showed a mirror-image pattern indicative of their enantiomeric relationship (see Figure S2 in the ESI). 

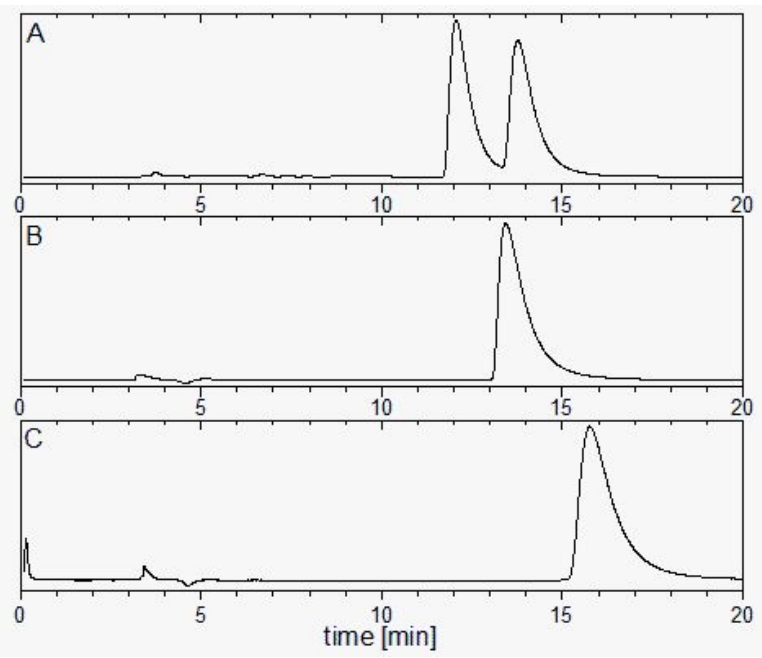

Figure 3. Chiral HPLC traces (Chiralpak IC, $\mathrm{CH}_{2} \mathrm{Cl}_{2} / \mathrm{MeOH} / \mathrm{NEt}_{3} / \mathrm{CF}_{3} \mathrm{COOH}$ 90:10:0.3:0.5, UV detection at $300 \mathrm{~nm}$ ) for the preparative resolution of rac-1 (A) and the corresponding analytical runs after the separation (B: (P,P)-1 and C: (M,M)-1; see text for assignment of the configurations).

The counterions for the tricationic chromium complex enantiomers after chiral HPLC resolution were assumed to be trifluoroacetates due to the large excess of the trifluoroacetic acid additive used in the HPLC eluents. ${ }^{19} \mathrm{~F}$ NMR spectra of the compounds confirmed this by showing resonances around ca. $-78 \mathrm{ppm}$, which can unambiguously be assigned to free trifluoroacetate (see ESI). ${ }^{10}$ The configurational stability under the experimental conditions was assessed by stirring enantiopure material in $\mathrm{H}_{2} \mathrm{O}$ at room temperature. The enantiopurity of the dissolved complex was monitored over $48 \mathrm{~h}$ by taking samples at certain intervals and determining the enantiomeric excess by chiral HPLC. Over the course of this timeframe, no deterioration of the enantiomeric excess through racemization was detectable. Similarly, enantiomerically resolved material was configurationally stable in the solid state over extended periods (several weeks) of storage at room temperature. The absolute configuration of the resolved enantiomers $(\mathbf{M}, \mathbf{M})-\mathbf{1}$ and $(\mathbf{P}, \mathbf{P})-\mathbf{1}$ was elucidated via computational methods (TD-DFT, $\operatorname{CASSCF}(7,12)-\operatorname{NEVPT} 2^{11}$ ) by calculating the CD spectrum of (M,M)-1 (see ESI for details). The good agreement of the TD-DFT derived spectral shape in the region of the ligand-centered UV-transitions (ca. $\lambda<350$ $\mathrm{nm}$ ) with the experimental CD spectrum of the second HPLC fraction permits the assignment of the first HPLC fraction as (P,P)-1 and the second as (M,M)-1 (see Figure 3). The metal centered transitions $>400 \mathrm{~nm}$ display an overall positive rotatory strength according to CASSCF-NEVPT calculations on (M,M)-1 confirming the assignment based on TD-DFT (see ESI). Finally, the CPL properties of the phosphorescent near-IR emission bands $\left(\lambda_{\mathrm{em}} \approx 738 / 775 \mathrm{~nm}\right)$ were measured for the enantiopure complex $(\mathbf{M}, \mathbf{M})-\mathbf{1}$ in deoxygenated $D_{2} \mathrm{O}$ (see Figure 4 and Figure S3 in the ESI). The CPL measurement confirmed a large maximum value for $\mathrm{g}_{\text {lum }}=-0.093$ at $775 \mathrm{~nm}$ (and a positive $\mathrm{g}_{\text {lum }}$ for the weaker high-energy transition), which is less than the value recently obtained by Piguet $^{9}$ ( $\mid g_{|u m|}$
$<0.2$ ) but which still represents a very large dissymmetry factor for a 3d-metal complex and

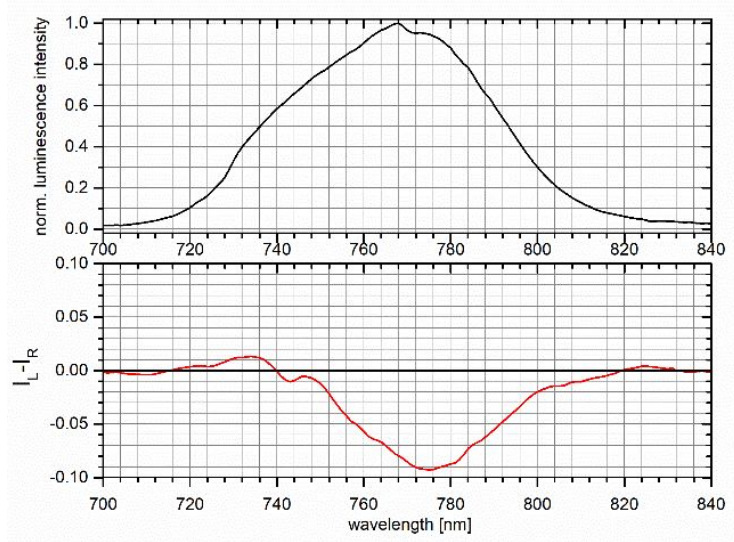

Figure 4. Steady-state emission (top, black) and CPL spectra (bottom, red) of the nearIR luminescence band ${ }^{2} \mathrm{E} /{ }^{2} \mathrm{~T}_{1} \rightarrow{ }^{4} \mathrm{~A}_{2}$ of $(\mathbf{M}, \mathbf{M})-\mathbf{1}$ in solution at room temperature (deoxygenated $\mathrm{D}_{2} \mathrm{O}, \mathrm{c}=10 \mu \mathrm{M}, \lambda_{\mathrm{exc}}=365 \mathrm{~nm}$ ).

which is on a par with many lanthanoid-based CPL emitters. ${ }^{2}$ Together with the superior general luminescence properties of $\left[\mathrm{Cr}(\mathrm{ddpd})_{2}\right]^{3+}$ (e.g. phosphorescence quantum yields up to $30 \%$ in solution) and high stability (configurational, thermal, photochemical), its resolved enantiomers are excellent candidates for the development of very efficient NIR-CPL luminophores based on the earth-abundant and cheap element chromium. Moreover, thanks to their ruby-like emission, optically active chromium(III) compounds could be advantageously used in the field of chiral optoelectronics and photonics.

Financial support from the German Research Foundation (DFG, Priority Program SPP 2102 "Light-controlled reactivity of metal complexes", grant no. HE 2778/15-1, SE 1448/8-1) is gratefully acknowledged. Parts of this research were conducted using the supercomputer Mogon and advisory services offered by Johannes Gutenberg University of Mainz (https://hpc.unimainz.de), which is a member of the AHRP and the Gauss Alliance.

\section{Conflicts of interest}

There are no conflicts to declare.

\section{Notes and references}

1 a) J. P. Riehl and G. Muller in Comprehensive Chiroptical Spectroscopy, Vol. 1 (Eds.: N. Berova, P. L. Polavarapu, K. Nakanishi, R. W. Woody), John Wiley \& Sons, Hoboken, 2012, pp. 65.; b) J. Kumar, T. Naashima and T. Kawai, J. Phys. Chem. Lett., 2015, 6, 3445; c) H. Tanaka, Y. Inoue and T. Mori, ChemPhotoChem, 2018, 2, 386; d) G. Longhi, E. Castiglioni, J. Koshoubu, G. Mazzeo and S. Abbate, Chirality, 2016, 28, 696; e) J. P. Riehl and F. S. Richardson, Chem. Rev., 1986, 86, 1. 
2 a) F. Zinna and L. Di Bari, Chirality, 2015, 27, 1; b) G. Muller in Luminescence of Lanthanide Ions in Coordination Compounds and Nanomaterials (Eds.: A. de Bettencourt-Dias), John Wiley \& Sons, Hoboken, 2014, pp. 77; c) R. Carr, N. H. Evans and D. Parker, Chem. Soc. Rev., 2012, 41, 7673; d) F. Zinna, U. Giovanella and L. Di Bari, Adv. Mater., 2015, 27, 1791; e) J. R. Brandt, X. Wang, Y. Yang, A. J. Campbell and M. J. Fuchter, J. Am. Chem. Soc., 2016, 138, 9743; f) F. Zinna, M. Pasini, F. Galeotti, C. Botta, L. Di Bari and U. Giovanella, Adv. Funct. Mater., 2017, 27, 1603719.

3 F. S. Richardson, Inorg. Chem., 1980, 19, 2806.

4 a) J. OuYang, J. Crassous, Coord. Chem. Rev., 2018, 376, 533; b) J. Kumar, T. Nakashima and T. Kawai, J. Phys. Chem. Lett. 2015, 6, 3445; c) E. M. Sanchez-Carnerero, A. R. Agarrabeitia, F. Moreno, B. L. Maroto, G. Muller, M. J. Ortiz, S. de la Moya, Chem. Eur. J., 2015, 21, 13488.

5 a) J. L. Lunkley, D. Shirotani, K. Yamanari, S. Kaizaki and G. Muller, J. Am. Chem. Soc., 2008, 130, 13814; b) J. L. Lunkley, D. Shirotani, K. Yamanari, S. Kaizaki and G. Muller, Inorg. Chem., 2011, 50, 12724; c) S. Di Pietro and L. Di Bari, Inorg. Chem., 2012, 51, 12007.

6 a) L. A. Büldt and O. S. Wenger, Chem. Sci., 2017, 8, 7359; b) D. Zare, B. Doistau, H. Nozary, C. Besnard, L. Guénée, Y. Suffren, A.-L. Pelé, A. Hauser and C. Piguet, Dalton Trans., 2017, 46, 8992; c) P. S. Wagenknecht and P. C. Ford, Coord. Chem. Rev., 2011, 255, 591; d) S. Otto, M. Dorn, C. Förster, M. Bauer, M. Seitz and K. Heinze, Coord. Chem. Rev., 2018, 359, 102.

7 a) G. L. Hilmes, H. G. Brittain, F. S. Richardson, Inorg. Chem., 1977, 16, 528; b) T. Tsubomura, M. Morita and I. Ohkouchi, J. Lumin., 1988, 40-41, 268; c) M. Morita, K. Eguchi, M. Shishikura, H. Nishikawa and M. Inoue, J. Lumin., 1984, 3132, 558; d) T. Tsubomura, I. Ohkouchi and M. Morita, Bull. Chem. Soc. Jpn., 1991, 64, 2341; e) R. D. Peacock and B. Stewart, J. Chem. Soc., Chem. Commun., 1982, 295; f) C. Emeis and L. Oosterhoff, Chem. Phys. Lett., 1967, 1, 129.

8 a) C. Wang, S. Otto, M. Dorn, E. Kreidt, J. Lebon, L. Srsan, P. Di Martino-Fumo, M. Gerhards, U. Resch-Genger, M. Seitz and K. Heinze, Angew. Chem. Int. Ed., 2018, 57, 1112; b) S. Otto, M. Grabolle, C. Förster, C. Kreitner, U. Resch-Genger and K. Heinze, Angew. Chem. Int. Ed., 2015, 54, 11572.

9 J.-R. Jiménez, B. Doistau, C. M. Cruz, C. Besnard, J. M. Cuerva, A. G. Campaña and C. Piguet, J. Am. Chem. Soc., 2019, 141, 13244.

10 J. W. Emsley and L. Phillips, Prog. Nucl. Magn. Reson. Spectrosc., 1971, 7, 1.

11 S. Otto, J. Harris, K. Heinze and C. Reber, Angew. Chem. Int. Ed., 2018, 57, 11069. 


\section{Strong Circularly Polarized Luminescence of an Octahedral Chromium(III) Complex}

Carolin Dee, ${ }^{a}$ Francesco Zinna, ${ }^{\mathrm{b}}$ Winald R. Kitzmann, ${ }^{\mathrm{c}}$ Gennaro Pescitelli, ${ }^{\mathrm{b}}$ Katja Heinze,${ }^{* \mathrm{c}}$ Lorenzo Di Bari*b and Michael Seitz ${ }^{* a}$

a Institute of Inorganic Chemistry, University of Tübingen, Auf der Morgenstelle 18, 72076 Tübingen, Germany

b Dipartimento di Chimica e Chimica Industriale, Università di Pisa, Via Moruzzi 13, 56124 Pisa, Italy.

c Institute of Inorganic Chemistry and Analytical Chemistry, Johannes Gutenberg University of Mainz, Duesbergweg 10-14, 55128 Mainz, Germany

Email: katja.heinze@uni-mainz.de, lorenzo.dibari@unipi.it, michael.seitz@uni-tuebingen.de

\section{Supplementary Information}

\section{Table of Contents}

1. Materials and Methods $\quad$ S2

2. Chiral HPLC / Configurational Stability Test S2

3. ECD and CPL measurements

4. Calculation of the Energy Barriers for Racemization Pathways S5

$\begin{array}{lll}\text { 5. Assignment of Absolute Configuration } & \text { S7 }\end{array}$

6. Cartesian Coordinates for Calculated Species S9

$\begin{array}{lll}\text { 7. } & \text { References } & \text { S41 }\end{array}$ 


\section{Materials and Methods}

NMR spectra were recorded on a Bruker AVII+400 spectrometer $\left({ }^{1} \mathrm{H}: 400 \mathrm{MHz},{ }^{19} \mathrm{~F}: 377 \mathrm{MHz}\right)$ using $\mathrm{CD}_{3} \mathrm{OD}(\geq 99.8 \% \mathrm{D})$ as the solvent. The racemic $\mathrm{Cr}$ complex $\left[\mathrm{Cr}(\mathrm{ddpd})_{2}\right]\left(\mathrm{BF}_{4}\right)_{3}$ was synthesized as described previously. ${ }^{1}$ NMR-grade $\mathrm{D}_{2} \mathrm{O}(>99.8 \% \mathrm{D})$ was used for the photophysical measurements.

\section{Chiral HPLC / Configurational Stability Test}

All chiral HPLC runs of the $\left[\mathrm{Cr}(\mathrm{ddpd})_{2}\right](\mathrm{X})_{3}$ complexes (rac-1 or enantioenriched samples) were performed on a Knauer Azura HPLC system (UV detection at $\lambda=300 \mathrm{~nm}$ ), equipped with a CHIRALPAK IC column (Daicel, particle size: $5 \mu \mathrm{m}$, internal diameter: $4.6 \mathrm{~mm}$, column length: $250 \mathrm{~mm}$ ) using $\mathrm{CH}_{2} \mathrm{Cl}_{2} / \mathrm{MeOH}(90: 10)$ with additional 0.5 vol.- $\% \mathrm{NEt}_{3}$ and 0.3 vol.- $\% \mathrm{CF}_{3} \mathrm{COOH}$ as mobile phase with a flow of $1.0 \mathrm{~mL} / \mathrm{min}$. All samples were filtered through a membrane filter (nylon, $0.45 \mu \mathrm{m}$ pore size, $13 \mathrm{~mm}$ diameter) in a stainless steel filter holder prior to injection.

Racemic $\left[\mathrm{Cr}(\mathrm{ddpd})_{2}\right]\left(\mathrm{BF}_{4}\right)_{3}(6.0 \mathrm{mg})$ was dissolved in $\mathrm{CH}_{2} \mathrm{Cl}_{2} / \mathrm{MeOH}(90: 10$, v/v, $5.5 \mathrm{~mL})$ and filtered through a membrane filter (vide infra). The filter was washed with additional $0.5 \mathrm{~mL}$ of the solvent mixture, to yield a concentration of ca. $1 \mathrm{mg} / \mathrm{mL}$. The solution was subjected to chiral HPLC in portions of $100 \mu \mathrm{L}$. The collected fractions of the respective enantiomers were combined and the solvents were removed in vacuo at room temperature. After drying in vacuo, samples of the enantiomers were redissolved in the HPLC solvent mixture, filtered, and injected to verify the enantiopurity. After the HPLC purification, the enantiopure complexes contain additional triethylammonium trifluoroacetate $\left(\mathrm{HNEt}_{3} \mathrm{CF}_{3} \mathrm{COO}\right)$. This raw material was washed repeatedly with $\mathrm{CH}_{2} \mathrm{Cl}_{2}$ which slowly removes the slightly soluble impurity triethylammonium trifluoroacetate. This procedure yields material with only a minimum presence of the salt. 
The counterions after chiral HPLC resolution was confirmed to be trifluoroacetate by mass spectrometry (ESI-MS, neg. mode: $\mathrm{m} / \mathrm{z}(\%)=113.11\left\{31 \%,\left[\mathrm{CF}_{3} \mathrm{COO}\right]\right\}, 226.96\{100 \%$, $\left.\left[2 \mathrm{CF}_{3} \mathrm{COO}+\mathrm{H}^{-}\right\}\right)$and by ${ }^{19} \mathrm{~F} \mathrm{NMR}$ spectroscopy ${ }^{2}$ (Figure S1):

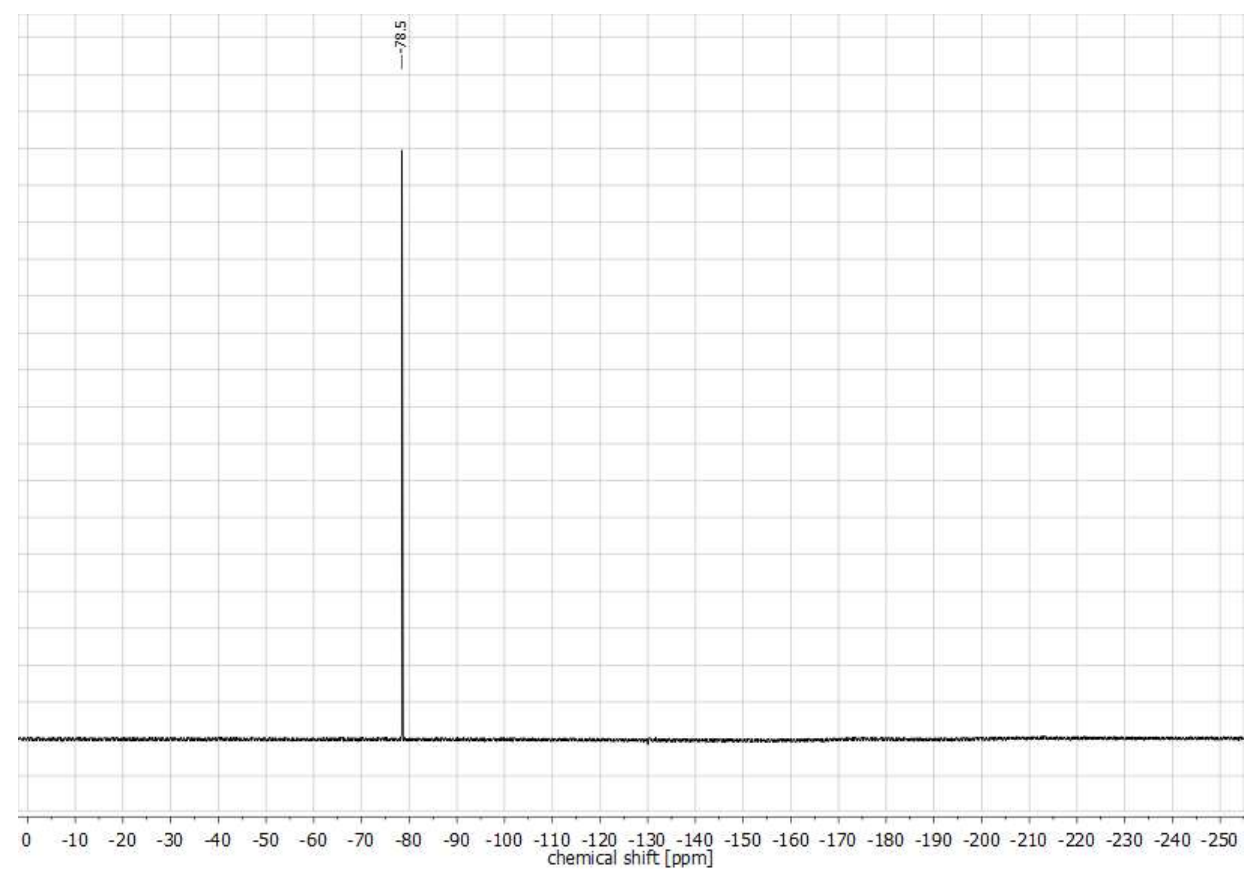

Figure S1. ${ }^{19} \mathrm{~F}$ NMR spectrum $\left(377 \mathrm{MHz}, \mathrm{CD}_{3} \mathrm{OD}\right)$ of $(\boldsymbol{M}, \boldsymbol{M})-1$.

Configurational stability test in solution

An enantiomerically pure sample of $(M, M)-1(0.3 \mathrm{mg})$ was stirred at room temperature in $\mathrm{H}_{2} \mathrm{O}$ $(1.0 \mathrm{~mL}, \mathrm{HPLC}$ grade). During the course of $48 \mathrm{~h}$, samples of $100 \mu \mathrm{l}$ were taken at certain intervals ( $1 \mathrm{~h}, 3 \mathrm{~h}, 24 \mathrm{~h}, 48 \mathrm{~h}$ ). These samples were immediately concentrated under a stream of air and the residues were taken up in $\mathrm{CH}_{2} \mathrm{Cl}_{2} / \mathrm{MeOH}(90: 10,100 \mu \mathrm{L})$. The solutions were filtered through a membrane filter (nylon, $0.45 \mu \mathrm{m}$ pore size), the filter was washed with additional solvent mixture $(100 \mu \mathrm{L})$, and the combined filtrates were concentrated. For chiral HPLC analysis, the dry samples were redissolved in $\mathrm{CH}_{2} \mathrm{Cl}_{2} / \mathrm{MeOH}(90: 10,100 \mu \mathrm{L})$ directly before the run. 


\section{ECD and CPL measurements}

The ECD spectra (Figure S2) were recorded with a Jasco J-715 spectropolarimeter (4 accumulations) on $10 \mu \mathrm{M}$ solutions in deoxygenated $\mathrm{D}_{2} \mathrm{O}$. CPL spectra were measured with a home-made spectrofluoropolarimeter ${ }^{3}$ in the configuration described before. ${ }^{4}$ The spectra were acquired on $10 \mu \mathrm{M}$ solutions in deoxygenated $\mathrm{D}_{2} \mathrm{O}$ under $365 \mathrm{~nm}$ irradiation, with $4 \mathrm{sec}$ integration time and 4 accumulations. The spectra were baseline corrected by subtracting the trace of the solvent.

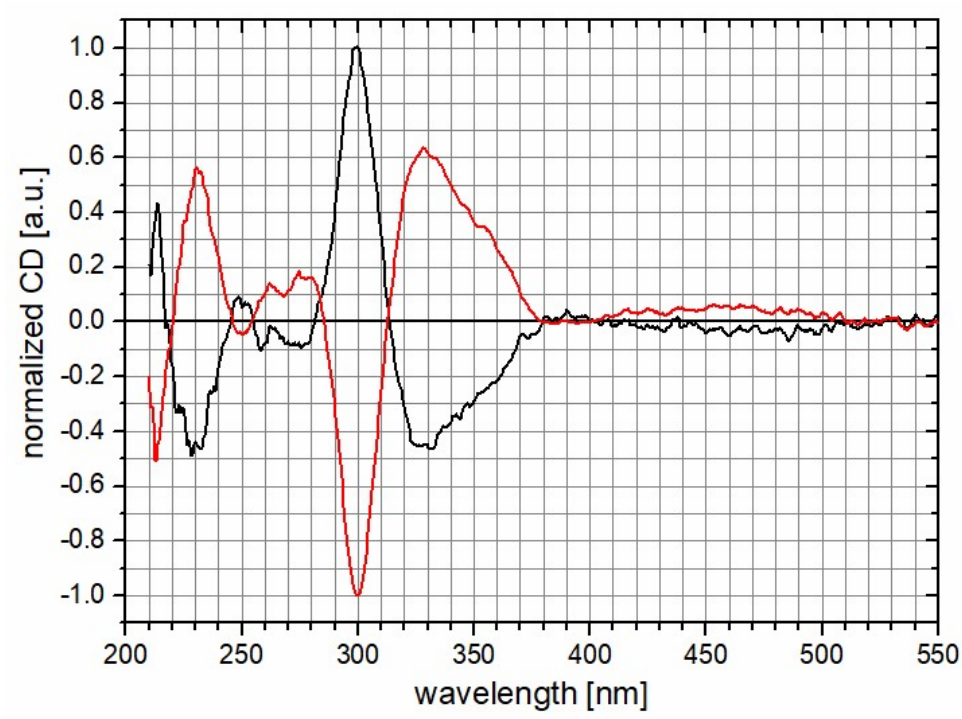

Figure S2. Normalized CD spectra (deoxygenated $\mathrm{D}_{2} \mathrm{O}, \mathrm{c}=10 \mu \mathrm{M}$ ) of the first chiral HPLC fraction (black) and the second fraction (red) - Mirror-image relationship indicating the enantiomeric nature of both fractions.
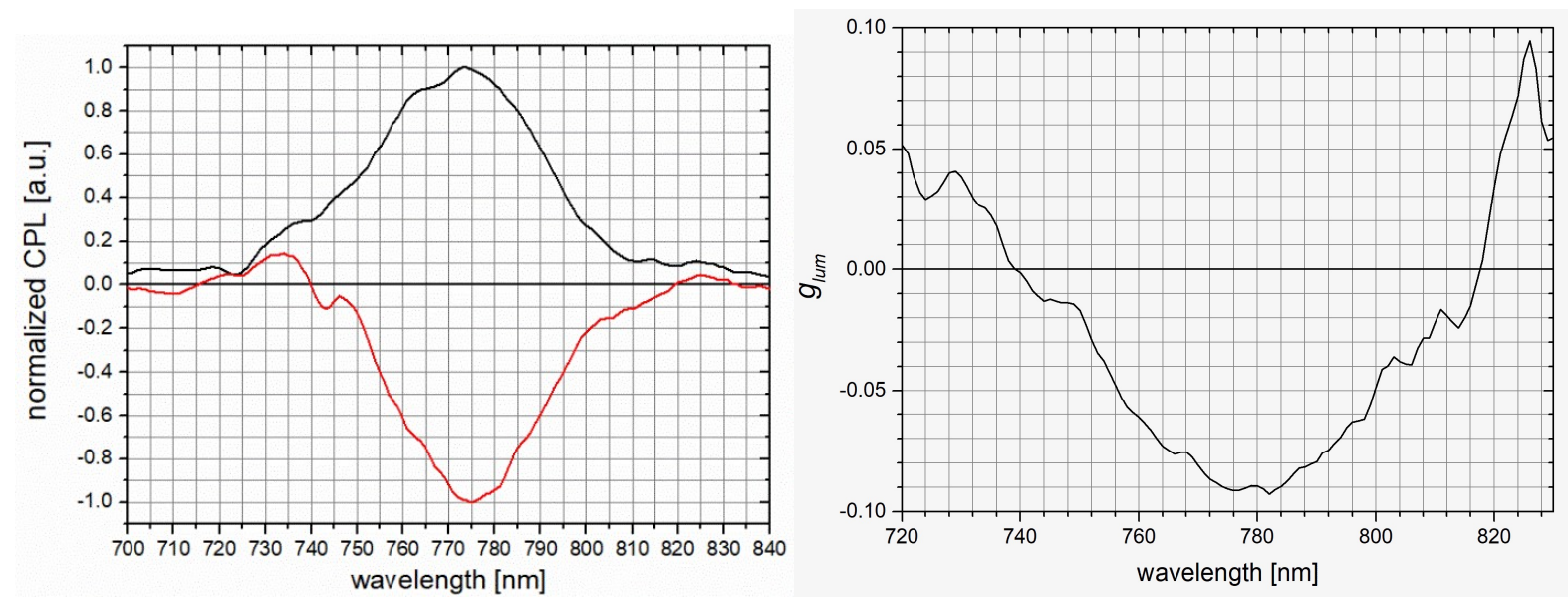

Figure S3. Left: Normalized CPL spectra (deoxygenated $D_{2} \mathrm{O}, \mathrm{c}=10 \mu \mathrm{M}$ ) of the first chiral HPLC fraction (black) and the second fraction (red) - Right: Plot of glum vs. the wavelength for $(M, M-1)$. 


\section{Calculation of the Energy Barriers for Racemization Pathways}

Racemization of $(M, M)$ - or $(P, P)-\left[\mathrm{Cr}(\mathrm{ddpd})_{2}\right]^{3+}$ can occur without changing the coordination number via inverting the boat conformations of the four six-membered chelate rings. Using DFT optimizations with constrained dihedral angles in the chelate rings, geometries of $\left[\mathrm{Cr}(\mathrm{ddpd})_{2}\right]^{3+}$ with one half-chair, one flattened ring and with fully flattened ligands were optimized with free enthalpy differences of 31,141 and $337 \mathrm{~kJ} / \mathrm{mol}$, respectively. These numbers show that the planarization of only one chelate ring is very unfavorable (Figure S4). Since completely flattened ligands might be avoided in the actual mechanism, a reaction path from $(M, M)$ - to $(P, P)$ $\left[\mathrm{Cr}(\mathrm{ddpd})_{2}\right]^{3+}$ was calculated using the nudged elastic band (NEB) method. The NEB method indeed favors a stepwise minimum energy path (Figure 2 in the manuscript). The inversion of both chelate rings of the first ligand is followed by the planarization and subsequent inversion of the first chelate ring on the second ddpd ligand. Finally, the last six-membered chelate-ring inverts.

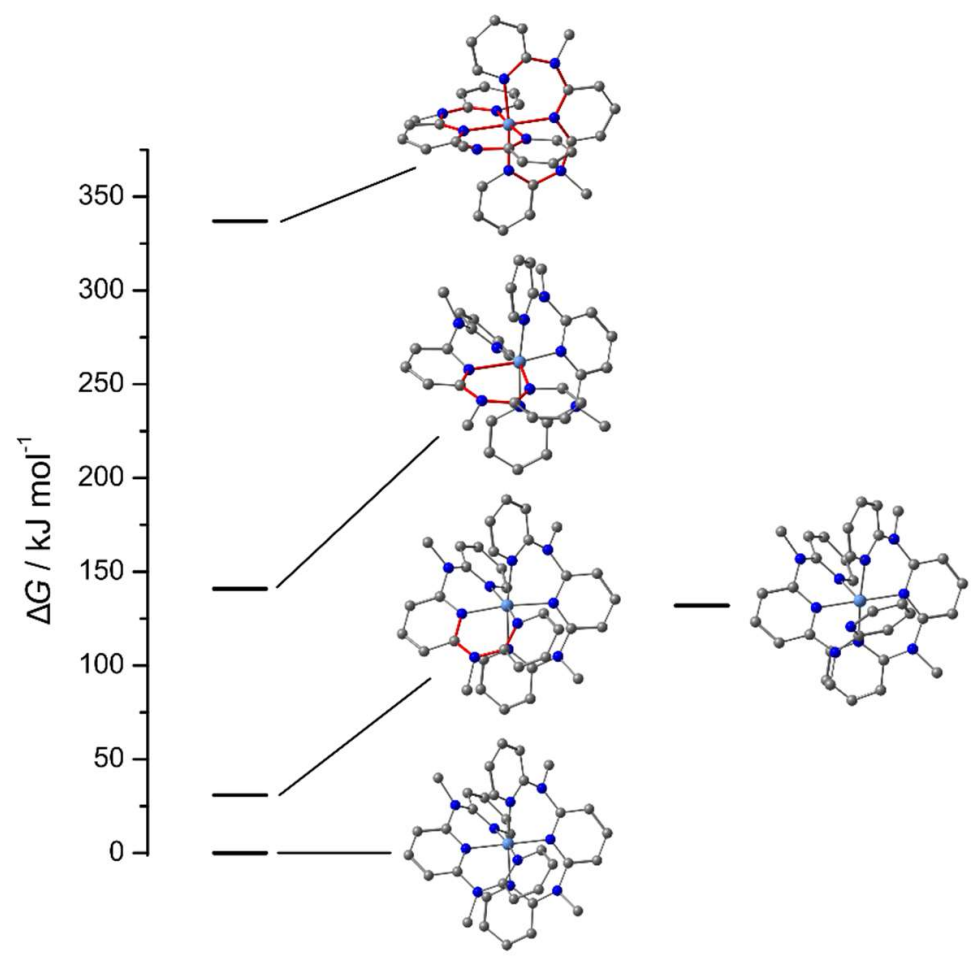

Figure S4. Optimized geometries of $\left[\mathrm{Cr}(\mathrm{ddpd})_{2}\right]^{3+}$ with constrained chelate rings indicated in red (left) and of $\left[\mathrm{Cr}(\mathrm{ddpd})\left(\mathrm{K}^{2} \mathrm{~N}-\mathrm{ddpd}\right)\right]^{3+}$ (right).

To investigate a conceivable dissociative pathway, the geometry of $\left[\mathrm{Cr}(\mathrm{ddpd})\left(\mathrm{K}^{2} \mathrm{~N}-\mathrm{ddpd}\right)\right]^{3+}$ was optimized using DFT (Figure S4, right). This yielded a free enthalpy difference of $132 \mathrm{~kJ} / \mathrm{mol}$. It 
was not possible to obtain the optimized geometry of 7-coordinate $\left[\mathrm{Cr}(\mathrm{ddpd})_{2}\left(\mathrm{H}_{2} \mathrm{O}\right)\right]^{3+}$. Instead, the calculation yielded 6-coordinate $\left[\mathrm{Cr}(\mathrm{ddpd})\left(\mathrm{k}^{2} \mathrm{~N}-\mathrm{ddpd}\right)\left(\mathrm{H}_{2} \mathrm{O}\right)\right]^{3+}$ with the dissociated pyridyl residue forming a hydrogen bond with the water ligand.

DFT calculations were carried out using the ORCA program package (version 4.1.1) ${ }^{5}$ using the B3LYP functional. ${ }^{6-8}$ Tight convergence criteria were chosen for geometry optimizations and frequency calculations (Keywords TightSCF and TightOpt, convergence criteria for the SCF part: energy change $1.0 \times 10^{-8} E_{\mathrm{h}}, 1$-El. energy change $1.0 \times 10^{-5} E_{\mathrm{h}}$, orbital gradient $1.0 \times 10^{-5}$, orbital rotation angle $1.0 \times 10^{-5}$, DIIS Error $5.0 \times 10^{-7}$; for geometry optimizations: energy change: $1.0 \times 10^{-6} E_{\mathrm{h}}$, max. gradient $1.0 \times 10^{-4} E_{\mathrm{h}} a_{0}^{-1}$, RMS gradient $3.0 \times 10^{-5} E_{\mathrm{h}} a_{0}^{-1}$, max. displacement $1.0 \times 10^{-3} a_{0}$, RMS displacement $6.0 \times 10^{-4} a_{0}$ ). All calculations make use of the resolution of identity (Split-RI-J) approach for the Coulomb term in combination with the chain-of-spheres approximation for the exchange term (COSX) ${ }^{9,10}$ The ZORA relativistic approximation was used to describe relativistic effects in all calculations. ${ }^{11}$ To account for solvent effects, a conductorlike screening model (CPCM) modeling acetonitrile was used in all calculations. ${ }^{12}$ Atom-pairwise dispersion correction was performed with the Becke-Johnson damping scheme (D3BJ). ${ }^{13,14}$ For the geometries of the ground state and with (partly) planarized ligands geometry optimizations were performed using Ahlrichs' split valence triple- $\xi$ basis set def2-TZVPP which comprises polarization functions for all non-hydrogen atoms. ${ }^{15,16}$ Dihedral angles were fixed to $0^{\circ}$ for the calculations of the structures with (partly) planarized ligands. For ground state geometries the presence of energy minima was checked by numerical frequency calculations. Explicit counter ions and/or solvent molecules were not taken into account. NEB calculations were performed using Ahlrichs' split valence polarization basis set def2-SVP basis with ground state geometries optimized using the same basis set. ${ }^{13,14}$ Seven intermediate images were calculated with initial path generation via the image dependent pair potential (IDPP) method ${ }^{17}$ and optimized using the Limited-memory Broyden-Fletcher-Goldfarb-Shanno (L-BFGS) algorithm. ${ }^{18}$ Tolerance for the maximum component of the atomic force perpendicular to the path was $5.0 \times 10^{-4} \mathrm{Eh} \mathrm{a}_{0}{ }^{-1}$ with a root-mean-square of $2.0 \times 10^{-4} \mathrm{Eh} a_{0}{ }^{-1}$. The spring constant was set to $1.0 \times 10^{-1}$ Eh $a_{0}{ }^{-2}$.

CASSCF $(7,12)-N E V P T 2$ calculations for metal-centered excited states were performed as previously described. ${ }^{19}$ 


\section{Assignment of Absolute Configuration}

To assign the absolute configuration of the enantiomers of $\left[\mathrm{Cr}(\mathrm{ddpd})_{2}\right]^{3+}$ and the elution order of its enantioseparation, experimental electronic circular dichroism (ECD) spectra were compared with those calculated by means of density functional theory (DFT). ${ }^{20,21}$ The X-ray geometry of rac-1 served as starting point to produce a DFT-optimized geometry (M06/def2-SVP) with $(M, M)$-chirality and $D_{2}$-symmetry, shown in Figure S5. Excited state calculations were then run with the time-dependent DFT method (TD-DFT). After a minimal screening of functionals and basis sets, ${ }^{22}$ final calculations were run at the CAM-B3LYP/def2-TZVP level of theory using a PCM solvent model for water. The comparison between experimental and calculated UV/ECD spectra is shown in Figure S6. The agreement is excellent between the ECD spectrum calculated for the $(M, M)$-enantiomer and the experimental trace recorded for the second eluted isomer. As it frequently happens with open-shell transition metal complexes with multichromophoric ligands, there is a very high densities of states in the short-wavelength region (see vertical bars in Figure S6). ${ }^{23,24}$ Moreover, a clear distinction between metal-centered and ligand-centered transitions is challenging by TD-DFT methods. To extract the metal-centered transitions, CASSCF $(7,12)-N E V P T 2$ calculations were performed additionally. ${ }^{19}$
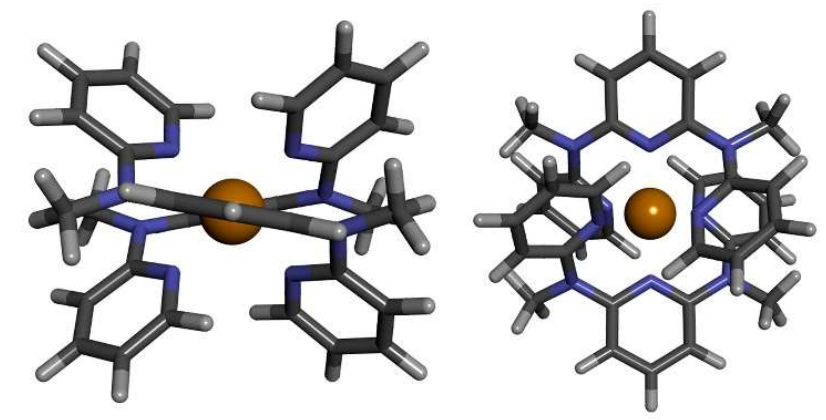

Figure S5. DFT-optimized structure of the cationic metal complex in $(\boldsymbol{M}, \boldsymbol{M})-1$ with $D_{2}$ symmetry seen along two different $C_{2}$ axes. 


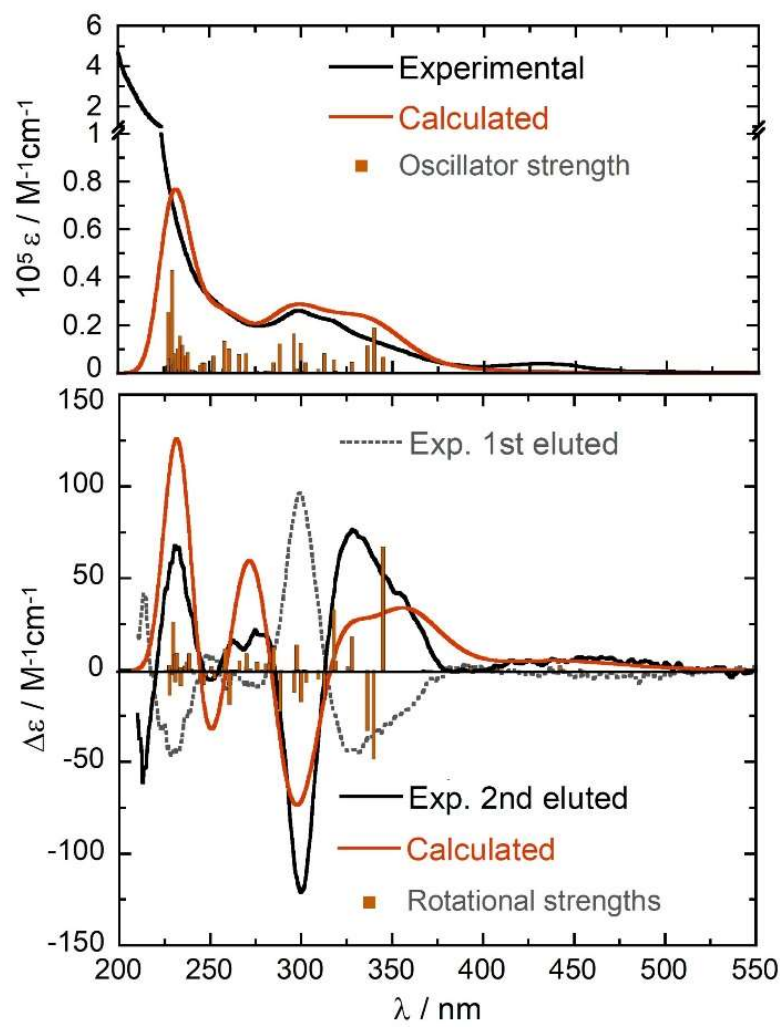

Figure S6. Comparison between the experimental and calculated UV/vis absorption (top) and ECD (bottom) spectra measured in $\mathrm{D}_{2} \mathrm{O}$ at $10^{-5} \mathrm{M}$ concentration, and TD-DFT-calculated spectra on $(\boldsymbol{M}, \boldsymbol{M})-1$ at the CAM-B3LYP/def2-TZVP/PCM//M06/def2-SVP level. Calculated spectra were plotted using an exponential bandwidth of $0.35 \mathrm{eV}$ and red-shifted by $33 \mathrm{~nm}$.

DFT/TD-DFT calculations for the assignment of absolute configurations were run with the Gaussian 16 package ${ }^{25}$ using default grids and convergence criteria. The starting geometry was extracted from the published X-ray structure of a racemic form of $\left[\mathrm{Cr}(\mathrm{ddpd})_{2}\right]^{3+}$ and had $(M, M)$ configuration. ${ }^{1}$ The tricationic metal complex was optimized at the M06/def2-SVP level in vacuo. TD-DFT calculations were run using B3LYP and CAM-B3LYP functionals, def2-SVP or def2TZVP basis set on all atoms, either in vacuo or including IEF-PCM solvent model for water. All calculations were run for $\left[\mathrm{Cr}(\mathrm{ddpd})_{2}\right]^{3+}$ in its quartet state using unrestricted wavefunctions; ground and excited states were checked for wavefunction stability and spin contamination. Up to 100 excited states (roots) were considered. UV/vis absorption and ECD spectra were plotted using the software SpecDis. ${ }^{26,27}$

The absorption bands at wavelengths $>400 \mathrm{~nm}$ (the metal-centered quartet transitions) were reproduced by CASSCF(7,12)-NEVPT2 calculations on $(\mathbf{M}, \mathbf{M})-1 .^{19}$ The calculated overall positive $C D$ intensity for $(\mathbf{M}, \mathbf{M})-1$ at wavelengths $>400 \mathrm{~nm}$ confirm the TD-DFT based 
assignment of the second fraction as (M,M)-1 $\left(434 \mathrm{~nm}: R^{\star} T=-4.5 \times 10^{40} \mathrm{cgs} ; 429 \mathrm{~nm}: R^{\star} T=-\right.$ $\left.3.4 \times 10^{40} \mathrm{cgs} ; 411 \mathrm{~nm}: R^{\star} T=-12.5 \times 10^{40} \mathrm{cgs}\right)$.

\section{Cartesian Coordinates for Calculated Species}

Cartesian Coordinates (in $\AA$ ) for the optimized geometries of constrained chelate rings (Figure S3), NEB calculations (Figure 2 in the manuscript) and the five-coordinate complex $\left[\mathrm{Cr}(\mathrm{ddpd})\left(\mathrm{k}^{2} \mathrm{~N}-\mathrm{ddpd}\right)\right]^{3+}$ (Figure S4):

$\left[\mathrm{Cr}(\mathrm{ddpd})_{2}\right]^{3+}$ with one half-chair:

$\begin{array}{llll}24 & 10.634778000 & 12.457922000 & 5.063104000 \\ 7 & 9.012260000 & 13.664918000 & 5.635481000 \\ 6 & 8.988788000 & 14.323422000 & 6.815651000 \\ 1 & 9.906857000 & 14.353730000 & 7.376477000 \\ 7 & 8.023550000 & 13.061364000 & 3.620616000 \\ 6 & 7.853464000 & 14.915969000 & 7.309190000 \\ 1 & 7.881250000 & 15.410296000 & 8.267528000 \\ 7 & 10.311847000 & 13.164149000 & 2.860345000 \\ 6 & 6.686841000 & 14.848172000 & 6.549204000 \\ 1 & 5.770218000 & 15.294113000 & 6.908482000 \\ 7 & 11.723999000 & 14.155526000 & 5.605300000 \\ 6 & 6.719747000 & 14.238368000 & 5.312428000 \\ 1 & 5.843488000 & 14.222993000 & 4.686366000 \\ 7 & 12.770385000 & 12.976580000 & 7.355545000 \\ 6 & 7.916525000 & 13.673981000 & 4.862550000 \\ 7 & 10.675374000 & 11.883625000 & 7.024539000 \\ 6 & 6.792570000 & 12.456893000 & 3.085861000 \\ 1 & 6.081305000 & 13.188704000 & 2.702507000 \\ 1 & 6.320176000 & 11.890852000 & 3.885604000 \\ 1 & 7.063798000 & 11.774641000 & 2.286610000 \\ 6 & 8.992063000 & 13.436078000 & 2.647376000 \\ 6 & 8.519165000 & 13.916158000 & 1.446198000 \\ 1 & 7.485388000 & 14.199501000 & 1.340121000 \\ 6 & 9.381664000 & 13.931210000 & 0.360928000 \\ 1 & 9.036715000 & 14.255496000 & -0.610361000\end{array}$




\begin{tabular}{|c|c|c|c|}
\hline & 11.581457000 & 15.272372000 & 4.85899 \\
\hline 1 & 10.768409000 & 15.273750000 & 4.151787000 \\
\hline & 12.420948000 & 16.351434000 & 4972497000 \\
\hline & 12.268261000 & 17.219349000 & 4.03000000 \\
\hline & 13.450647000 & 16.286541000 & 5.90987800 \\
\hline & 14.129938000 & 17.117066000 & 6010208006 \\
\hline & 13.582005000 & 15.166956000 & 6.70437400 \\
\hline & 14.343604000 & 15.126253000 & 7464158000 \\
\hline & 12.682566000 & 14.106280000 & 6.54605000 \\
\hline & 14.046400000 & 12.747368000 & 8.05193500 \\
\hline & 14.852787000 & 12.904238000 & 1.04140500 \\
\hline & 14.072411000 & 11.715946000 & 8.38746800 \\
\hline & 14.181768000 & 13.407238000 & 8.90835800 \\
\hline & 11.648433000 & 12.312220000 & 7.87261700 \\
\hline & 11.567818000 & 12.078455000 & 9.236330000 \\
\hline & 12.334931000 & 12.451694000 & 9.89333900 \\
\hline & 10.470498000 & 11.401125000 & 9.73772900 \\
\hline & 10.387762000 & 11.209123000 & 10.79 \\
\hline & 12.407366000 & 11.904387000 & 4.1612820 \\
\hline & 13.030561000 & 11.135963000 & 5.1165220 \\
\hline & 12.480530000 & 10.972363000 & 6.02235800 \\
\hline & 12.381619000 & 12.484167000 & 1.8428610 \\
\hline & 14.250428000 & 10.537432000 & 4.99049400 \\
\hline & 14.661751000 & 9.977766000 & 5.815737000 \\
\hline & 14.885378000 & 10.632590000 & 3.75694400 \\
\hline & 15.835661000 & 10.152799000 & 3.57302 \\
\hline & 14.242446000 & 11.290358000 & 2.74193100 \\
\hline & 14.677081000 & 11.266910000 & 1.761090000 \\
\hline & 13.002396000 & 11.933904000 & 2.9505040 \\
\hline & 13.299545000 & 12.846543000 & 0.72408200 \\
\hline & 13.326499000 & 12.060477000 & -0.02733700 \\
\hline & 14.291229000 & 13.022435000 & 1.11753500 \\
\hline & 12.974913000 & 13.774340000 & 0.2764880 \\
\hline & 11.122849000 & 13.063139000 & 1.786942 \\
\hline
\end{tabular}




$\begin{array}{cccc}6 & 10.655760000 & 13.447958000 & 0.513660000 \\ 1 & 11.265631000 & 13.316654000 & -0.359127000 \\ 7 & 9.724951000 & 10.676627000 & 4.641404000 \\ 7 & 8.547356000 & 10.860690000 & 6.667809000 \\ 6 & 9.964005000 & 10.054126000 & 3.466213000 \\ 1 & 10.776119000 & 10.438644000 & 2.873739000 \\ 6 & 9.209638000 & 8.998397000 & 3.021854000 \\ 1 & 9.435634000 & 8.541129000 & 2.071347000 \\ 6 & 8.158960000 & 8.557380000 & 3.823543000 \\ 1 & 7.537966000 & 7.730830000 & 3.509103000 \\ 6 & 7.928233000 & 9.164088000 & 5.042300000 \\ 1 & 7.145750000 & 8.804330000 & 5.688828000 \\ 6 & 8.745514000 & 10.224855000 & 5.443607000 \\ 6 & 7.204427000 & 10.764324000 & 7.259408000 \\ 1 & 6.474333000 & 10.866185000 & 6.461947000 \\ 1 & 7.073526000 & 11.587815000 & 7.954754000 \\ 1 & 7.037441000 & 9.821929000 & 7.780421000 \\ 6 & 9.589483000 & 11.232808000 & 7.522374000 \\ 6 & 9.475457000 & 10.971381000 & 8.881844000 \\ 1 & 8.628884000 & 10.423993000 & 9.259006000\end{array}$

$\left[\mathrm{Cr}(\mathrm{ddpd})_{2}\right]^{3+}$ with one flattened ring:

$\begin{array}{llll}24 & 10.634778000 & 12.457922000 & 5.063104000 \\ 7 & 9.012260000 & 13.664918000 & 5.635481000 \\ 6 & 8.988788000 & 14.323422000 & 6.815651000 \\ 1 & 9.906857000 & 14.353730000 & 7.376477000 \\ 7 & 8.023550000 & 13.061364000 & 3.620616000 \\ 6 & 7.853464000 & 14.915969000 & 7.309190000 \\ 1 & 7.881250000 & 15.410296000 & 8.267528000 \\ 7 & 10.311847000 & 13.164149000 & 2.860345000 \\ 6 & 6.686841000 & 14.848172000 & 6.549204000 \\ 1 & 5.770218000 & 15.294113000 & 6.908482000 \\ 7 & 11.723999000 & 14.155526000 & 5.605300000 \\ 6 & 6.719747000 & 14.238368000 & 5.312428000\end{array}$




\begin{tabular}{|c|c|c|c|}
\hline 1 & 5.843488000 & 14.222993000 & 4.686366000 \\
\hline 7 & 12.770385000 & 12.976580000 & 7.355545000 \\
\hline 6 & 7.916525000 & 13.673981000 & 4.862550000 \\
\hline 7 & 10.675374000 & 11.883625000 & 7.024539000 \\
\hline 6 & 6.792570000 & 12.456893000 & 3.085861000 \\
\hline 1 & 6.081305000 & 13.188704000 & 2.702507000 \\
\hline 1 & 6.320176000 & 11.890852000 & 3.885604000 \\
\hline 1 & 7.063798000 & 11.774641000 & 2.286610000 \\
\hline$v$ & 8.992063000 & 13.436078000 & 2.647376000 \\
\hline 6 & 8.519165000 & 13.916158000 & 1.446198000 \\
\hline 1 & 7.485388000 & 14.199501000 & 1.340121000 \\
\hline 6 & 9.381664000 & 13.931210000 & 0.360928000 \\
\hline 1 & 9.036715000 & 14.255496000 & -0.610361000 \\
\hline 6 & 11.581457000 & 15.272372000 & 4.858994000 \\
\hline 1 & 10.768409000 & 15.273750000 & 4.151787000 \\
\hline 0 & 12.420948000 & 16.351434000 & 4.972497000 \\
\hline 1 & 12.268261000 & 17.219349000 & 4.350055000 \\
\hline 6 & 13.450647000 & 16.286541000 & 5.909878000 \\
\hline 1 & 14.129938000 & 17.117066000 & 6.040228000 \\
\hline 6 & 13.582005000 & 15.166956000 & 6.704374000 \\
\hline 1 & 14.343604000 & 15.126253000 & 7.464158000 \\
\hline 6 & 12.682566000 & 14.106280000 & 6.546050000 \\
\hline U & 14.046400000 & 12.747368000 & 8.051935000 \\
\hline 1 & 14.852787000 & 12.904238000 & 7.341405000 \\
\hline 1 & 14.072411000 & 11.715946000 & 8.387468000 \\
\hline 1 & 14.181768000 & 13.407238000 & 8.908358000 \\
\hline 6 & 11.648433000 & 12.312220000 & 7.872617000 \\
\hline 6 & 11.567818000 & 12.078455000 & 9.236330000 \\
\hline 1 & 12.334931000 & 12.451694000 & 9.893339000 \\
\hline$\sigma$ & 10.470498000 & 11.401125000 & 9.737729000 \\
\hline 1 & 10.387762000 & 11.209123000 & 10.797944000 \\
\hline 7 & 12.407366000 & 11.904387000 & 4.161282000 \\
\hline 6 & 13.030561000 & 11.135963000 & 5.116522000 \\
\hline & 12.480530000 & 10.972363000 & 6.022358000 \\
\hline
\end{tabular}




\begin{tabular}{llll}
7 & 12.381619000 & 12.484167000 & 1.842861000 \\
6 & 14.250428000 & 10.537432000 & 4.990494000 \\
1 & 14.661751000 & 9.977766000 & 5.815737000 \\
6 & 14.885378000 & 10.632590000 & 3.756944000 \\
1 & 15.835661000 & 10.152799000 & 3.573021000 \\
6 & 14.242446000 & 11.290358000 & 2.741931000 \\
1 & 14.677081000 & 11.266910000 & 1.761090000 \\
6 & 13.002396000 & 11.933904000 & 2.950504000 \\
6 & 13.299545000 & 12.846543000 & 0.724082000 \\
1 & 13.326499000 & 12.060477000 & -0.027337000 \\
1 & 14.291229000 & 13.022435000 & 1.117535000 \\
1 & 12.974913000 & 13.774340000 & 0.276488000 \\
6 & 11.122849000 & 13.063139000 & 1.786942000 \\
6 & 10.655760000 & 13.447958000 & 0.513660000 \\
1 & 11.265631000 & 13.316654000 & -0.359127000 \\
7 & 9.724951000 & 10.676627000 & 4.641404000 \\
7 & 8.547356000 & 10.860690000 & 6.667809000 \\
6 & 9.964005000 & 10.054126000 & 3.466213000 \\
1 & 10.776119000 & 10.438644000 & 2.873739000 \\
6 & 9.209638000 & 8.998397000 & 3.021854000 \\
1 & 9.435634000 & 8.541129000 & 2.071347000 \\
6 & 8.158960000 & 8.557380000 & 3.823543000 \\
1 & 7.537966000 & 7.730830000 & 3.509103000 \\
6 & 7.928233000 & 9.164088000 & 5.042300000 \\
1 & 7.145750000 & 8.804330000 & 5.688828000 \\
6 & 8.745514000 & 10.224855000 & 5.443607000 \\
6 & 7.204427000 & 10.764324000 & 7.259408000 \\
1 & 6.474333000 & 10.866185000 & 6.461947000 \\
1 & 7.073526000 & 11.587815000 & 7.954754000 \\
1 & 7.037441000 & 9.821929000 & 7.780421000 \\
\hline 6 & 9.589483000 & 11.232808000 & 7.522374000 \\
\hline 1 & 8.475457000 & 10.971381000 & 8.881844000 \\
\hline & 8.628884000 & 10.423993000 & 9.259006000
\end{tabular}


$\left[\mathrm{Cr}(\mathrm{ddpd})_{2}\right]^{3+}$ with fully planarized ligands:

\begin{tabular}{lrrr}
24 & 0.194337000 & 0.103937000 & 0.639206000 \\
7 & -0.246153000 & -0.156350000 & 2.672886000 \\
7 & 0.618343000 & 0.357652000 & -1.398737000 \\
7 & -1.593250000 & -0.844703000 & 0.023159000 \\
7 & 2.016210000 & 1.081091000 & 1.029588000 \\
7 & -0.825627000 & 1.943944000 & 0.773424000 \\
7 & 1.224679000 & -1.732966000 & 0.738023000 \\
6 & -1.418095000 & -0.746003000 & 3.086621000 \\
6 & -1.639387000 & -1.038176000 & 4.435719000 \\
6 & -0.823148000 & -0.509479000 & 5.399402000 \\
6 & 0.283946000 & 0.196679000 & 5.002836000 \\
6 & 0.632985000 & 0.256544000 & 3.651253000 \\
1 & -2.460280000 & -1.663427000 & 4.727119000 \\
1 & 0.887652000 & 0.687481000 & 5.740332000 \\
6 & -1.823493000 & -1.023373000 & -1.309588000 \\
6 & -2.911174000 & -1.657256000 & -1.844718000 \\
6 & -3.837952000 & -2.209046000 & -0.969525000 \\
6 & -3.634075000 & -2.048509000 & 0.374641000 \\
6 & -2.530619000 & -1.314578000 & 0.865212000 \\
1 & -4.685310000 & -2.776341000 & -1.326408000 \\
1 & -1.089384000 & -0.642435000 & -1.980832000 \\
1 & -3.005250000 & -1.740268000 & -2.916610000 \\
1 & -4.304479000 & -2.528924000 & 1.061799000 \\
6 & 2.513331000 & 1.286023000 & 2.261256000 \\
6 & 3.673381000 & 2.073600000 & 2.439943000 \\
6 & 4.373011000 & 2.557502000 & 1.365628000 \\
6 & 3.900248000 & 2.277711000 & 0.089770000 \\
6 & 2.734373000 & 1.572940000 & -0.019611000 \\
1 & 5.255210000 & 3.161256000 & 1.521234000 \\
1 & 3.994858000 & 2.342284000 & 3.428528000 \\
\hline 6 & 4.396387000 & 2.622383000 & -0.803956000 \\
\hline 1 & 2.345873000 & 1.396239000 & -0.996089000 \\
\hline 6.142642000 & 1.444224000 & -2.100378000
\end{tabular}




\begin{tabular}{lrrr}
6 & 0.289967000 & 1.522571000 & -3.487468000 \\
6 & 1.168744000 & 0.691192000 & -4.132288000 \\
6 & 1.765335000 & -0.312754000 & -3.415013000 \\
6 & 1.364149000 & -0.563522000 & -2.099068000 \\
1 & -0.249774000 & 2.256602000 & -4.051746000 \\
1 & 2.510365000 & -0.927090000 & -3.881523000 \\
6 & -1.309495000 & 2.347989000 & 1.983583000 \\
6 & -2.068055000 & 3.466358000 & 2.193043000 \\
6 & -2.424879000 & 4.226165000 & 1.085317000 \\
6 & -1.929575000 & 3.860448000 & -0.137339000 \\
6 & -1.058557000 & 2.755484000 & -0.272533000 \\
1 & -3.088248000 & 5.074535000 & 1.169951000 \\
1 & -1.072200000 & 1.740289000 & 2.826155000 \\
1 & -2.398160000 & 3.706954000 & 3.191723000 \\
1 & -2.241996000 & 4.404691000 & -1.008109000 \\
6 & 1.861797000 & -2.301377000 & -0.300935000 \\
6 & 2.679712000 & -3.437683000 & -0.105416000 \\
6 & 2.773719000 & -4.042941000 & 1.119068000 \\
6 & 2.049249000 & -3.503221000 & 2.174848000 \\
6 & 1.313815000 & -2.375028000 & 1.938278000 \\
1 & 3.412684000 & -4.903672000 & 1.252240000 \\
1 & 3.277932000 & -3.810911000 & -0.914473000 \\
1 & 2.060579000 & -3.929821000 & 3.165914000 \\
1 & 0.759711000 & -1.961549000 & 2.749538000 \\
\hline 1 & -0.603340000 & 2.495703000 & -1.561162000 \\
6 & -0.469229000 & 3.765601000 & -2.362512000 \\
1 & -0.393997000 & 4.602914000 & -1.682995000 \\
1 & 0.449819000 & 3.733689000 & -2.930679000 \\
\hline 1 & -1.314899000 & 3.903995000 & -3.030909000 \\
\hline 1.903071000 & -1.740922000 & -1.572922000 \\
\hline 1.462050000 & -2.581458000 & -3.475882000
\end{tabular}




$\begin{array}{rrrr}7 & -2.416820000 & -1.252510000 & 2.249372000 \\ 7 & 1.856759000 & 0.897996000 & 3.425948000 \\ 6 & -3.772441000 & -1.252288000 & 2.912106000 \\ 1 & -4.507846000 & -0.898993000 & 2.201860000 \\ 1 & -4.039971000 & -2.244449000 & 3.265339000 \\ 1 & -3.768696000 & -0.557684000 & 3.740022000 \\ 6 & 2.835074000 & 0.671047000 & 4.550497000 \\ 1 & 3.811123000 & 0.468602000 & 4.129956000 \\ 1 & 2.884380000 & 1.532285000 & 5.211657000 \\ 1 & 2.541895000 & -0.205284000 & 5.111028000 \\ 1 & -1.046693000 & -0.648688000 & 6.447246000 \\ 1 & 1.388717000 & 0.828658000 & -5.181000000\end{array}$

NEB \#1:

$\begin{array}{lrrr}24 & -0.000085000 & 0.000888000 & 0.000253000 \\ 7 & -0.091023000 & -2.052760000 & -0.086249000 \\ 6 & 0.884859000 & -2.745412000 & -0.715287000 \\ 1 & 1.569522000 & -2.167731000 & -1.316003000 \\ 7 & -2.053586000 & -1.988559000 & 1.210512000 \\ 6 & 1.027682000 & -4.103621000 & -0.588001000 \\ 1 & 1.834570000 & -4.611595000 & -1.094810000 \\ 7 & -2.034199000 & -0.000496000 & -0.095014000 \\ 6 & 0.113162000 & -4.788757000 & 0.210524000 \\ 1 & 0.191126000 & -5.859726000 & 0.339944000 \\ 7 & 0.191078000 & 0.000730000 & -2.048492000 \\ 6 & -0.917198000 & -4.099316000 & 0.815357000 \\ 1 & -1.659811000 & -4.628061000 & 1.389924000 \\ 7 & 2.084339000 & 1.382703000 & -1.840314000 \\ 6 & -1.013260000 & -2.713917000 & 0.635101000 \\ 7 & 2.034201000 & 0.000888000 & 0.095121000 \\ 6 & -2.748954000 & -2.603010000 & 2.350455000 \\ 1 & -3.457787000 & -3.374198000 & 2.046916000 \\ 1 & -2.003352000 & -3.036342000 & 3.012078000 \\ 1 & -3.276702000 & -1.822135000 & 2.890063000\end{array}$




\begin{tabular}{|c|c|c|c|}
\hline & -2.741265000 & -0.981898000 & 0.517110000 \\
\hline & -4.129131000 & -0.996776000 & 0.477268000 \\
\hline & -4.680242000 & -1.792662000 & 0.950207000 \\
\hline & -4.787647000 & -0.004343000 & -0.226778000 \\
\hline & -5.867933000 & -0.005771000 & -0.278452000 \\
\hline & -0.720389000 & -0.644303000 & -2.810685000 \\
\hline & -1.402524000 & -1.297362000 & -2.289596000 \\
\hline & -0.804839000 & -0.470693000 & -4.168658000 \\
\hline & -1.562409000 & -0.992885000 & -4.733790000 \\
\hline & 0.103455000 & 0.393239000 & -4.778645000 \\
\hline & 0.070643000 & 0.559943000 & -5.846784000 \\
\hline & 1.070820000 & 1.016322000 & -4.017874000 \\
\hline & 1.810652000 & 1.642911000 & -4.488205000 \\
\hline & 1.108687000 & 0.788073000 & -2.63 \\
\hline & 2.752816000 & 2.576395000 & -2.377955000 \\
\hline & 1.997895000 & 3.219069000 & -2.823507000 \\
\hline & 3.216004000 & 3.109347000 & -1.552780000 \\
\hline & 3.511485000 & 2.335932000 & -3.123538000 \\
\hline & 2.756371000 & 0.683018000 & -0.827 \\
\hline & 4.143650000 & 0.708206000 & -0.775871000 \\
\hline & 4.707954000 & 1.236641000 & -1.526175000 \\
\hline & 4.788086000 & -0.002297000 & 0.221174000 \\
\hline & 5.868473000 & -0.003467000 & 0.270665000 \\
\hline & -0.101451000 & 2.054480000 & 0.078163000 \\
\hline & 0.811060000 & 2.747861000 & 0.795175000 \\
\hline & 1.437790000 & 2.170547000 & 1.456366000 \\
\hline & -1.934740000 & 1.988628000 & -1.395804000 \\
\hline & 0.963433000 & 4.106340000 & 0.682394000 \\
\hline 1 & 1.719495000 & 4.614691000 & 1.262000000 \\
\hline & 0.125404000 & 4.791020000 & -0.196391000 \\
\hline & 0.213854000 & 5.862124000 & -0.317499000 \\
\hline & -0.844054000 & 4.100825000 & -0.894041000 \\
\hline & -1.531124000 & 4.629019000 & -1.534482000 \\
\hline & -0.954095000 & 2.715103000 & -0.724783000 \\
\hline
\end{tabular}




$\begin{array}{lrrr}6 & -2.520893000 & 2.602876000 & -2.595770000 \\ 1 & -3.258181000 & 3.371081000 & -2.359871000 \\ 1 & -1.717448000 & 3.040026000 & -3.182950000 \\ 1 & -2.991999000 & 1.821051000 & -3.184119000 \\ 6 & -2.682154000 & 0.979352000 & -0.771655000 \\ 6 & -4.067538000 & 0.990093000 & -0.864528000 \\ 1 & -4.572760000 & 1.785304000 & -1.386928000 \\ 7 & -0.000085000 & 0.000888000 & 2.057842000 \\ 7 & 1.904605000 & -1.380694000 & 2.027339000 \\ 6 & -0.978914000 & 0.645323000 & 2.731730000 \\ 1 & -1.609491000 & 1.298395000 & 2.149429000 \\ 6 & -1.189844000 & 0.471230000 & 4.075831000 \\ 1 & -1.997146000 & 0.993153000 & 4.567620000 \\ 6 & -0.342265000 & -0.392603000 & 4.767781000 \\ 1 & -0.475188000 & -0.560001000 & 5.828001000 \\ 6 & 0.692439000 & -1.014952000 & 4.100703000 \\ 1 & 1.385517000 & -1.641683000 & 4.637599000 \\ 6 & 0.858960000 & -0.786050000 & 2.729244000 \\ 6 & 2.519009000 & -2.575039000 & 2.624769000 \\ 1 & 1.725247000 & -3.216521000 & 2.998739000 \\ 1 & 3.055729000 & -3.108540000 & 1.845933000 \\ 1 & 3.205183000 & -2.335618000 & 3.437753000 \\ 6 & 2.667406000 & -0.682739000 & 1.079844000 \\ 6 & 4.053615000 & -0.711065000 & 1.155133000 \\ 1 & 4.545432000 & -1.240114000 & 1.954334000\end{array}$

NEB \#2:

$\begin{array}{lrrr}24 & 0.000155000 & 0.001794000 & -0.004132000 \\ 7 & 0.026286000 & -2.085673000 & -0.238049000 \\ 6 & 1.096243000 & -2.670703000 & -0.835707000 \\ 1 & 1.891774000 & -2.016887000 & -1.169825000 \\ 7 & -2.115204000 & -2.251242000 & 0.773056000 \\ 6 & 1.205271000 & -4.035369000 & -1.020321000 \\ 1 & 2.092850000 & -4.449524000 & -1.492427000\end{array}$




\begin{tabular}{lrrr}
7 & -2.082294000 & -0.007366000 & -0.096421000 \\
6 & 0.141562000 & -4.842206000 & -0.598478000 \\
1 & 0.166986000 & -5.919165000 & -0.753320000 \\
7 & 0.037142000 & 0.018060000 & -2.119496000 \\
6 & -0.966911000 & -4.252093000 & -0.007878000 \\
1 & -1.815182000 & -4.862513000 & 0.280610000 \\
7 & 2.265054000 & 0.861554000 & -2.156993000 \\
6 & -1.005112000 & -2.853799000 & 0.166531000 \\
7 & 2.104100000 & -0.003401000 & 0.099589000 \\
6 & -2.905193000 & -3.121321000 & 1.661438000 \\
1 & -3.570224000 & -3.797351000 & 1.108566000 \\
1 & -2.216327000 & -3.713417000 & 2.267541000 \\
1 & -3.502672000 & -2.495115000 & 2.327106000 \\
6 & -2.780670000 & -1.127886000 & 0.259489000 \\
6 & -4.175669000 & -1.168541000 & 0.156569000 \\
1 & -4.714703000 & -2.084302000 & 0.367475000 \\
6 & -4.861150000 & -0.026016000 & -0.235092000 \\
1 & -5.947584000 & -0.034460000 & -0.294175000 \\
6 & -1.056146000 & -0.424363000 & -2.794423000 \\
1 & -1.926735000 & -0.677273000 & -2.206656000 \\
6 & -1.099006000 & -0.561279000 & -4.167556000 \\
1 & -2.018248000 & -0.887617000 & -4.646817000 \\
6 & 0.072741000 & -0.309590000 & -4.889760000 \\
1 & 0.110044000 & -0.465851000 & -5.965922000 \\
6 & 1.202866000 & 0.118426000 & -4.210455000 \\
1 & 2.129057000 & 0.278071000 & -4.750848000 \\
6 & 1.153446000 & 0.316242000 & -2.813730000 \\
6 & 3.133168000 & 1.693967000 & -3.013319000 \\
1 & 2.498838000 & 2.291135000 & -3.670195000 \\
\hline 1 & 3.712873000 & 2.370068000 & -2.382608000 \\
\hline 6 & 3.818815000 & 1.095461000 & -3.626990000 \\
\hline 1.856476000 & 0.369297000 & -0.983726000 \\
\hline & 4.255858000 & 0.297236000 & -0.952935000 \\
\hline & -83771000 & 0.493206000 & -1.846110000
\end{tabular}




\begin{tabular}{lrrr}
6 & 4.896633000 & -0.032444000 & 0.231603000 \\
1 & 5.983591000 & -0.045470000 & 0.283601000 \\
7 & 0.005808000 & 2.089502000 & 0.218200000 \\
6 & 1.028331000 & 2.682458000 & 0.886760000 \\
1 & 1.807947000 & 2.034338000 & 1.265706000 \\
7 & -2.059132000 & 2.242746000 & -0.949483000 \\
6 & 1.107965000 & 4.046893000 & 1.088940000 \\
1 & 1.959218000 & 4.467503000 & 1.618541000 \\
6 & 0.061347000 & 4.843378000 & 0.609122000 \\
1 & 0.060753000 & 5.918930000 & 0.775519000 \\
6 & -0.997656000 & 4.244747000 & -0.058775000 \\
1 & -1.831160000 & 4.848227000 & -0.400013000 \\
6 & -1.005246000 & 2.848271000 & -0.250652000 \\
6 & -2.778034000 & 3.119364000 & -1.890270000 \\
1 & -3.491275000 & 3.783465000 & -1.385070000 \\
1 & -2.045792000 & 3.723586000 & -2.429847000 \\
1 & -3.313910000 & 2.498606000 & -2.611080000 \\
6 & -2.756211000 & 1.107007000 & -0.512844000 \\
6 & -4.155424000 & 1.127424000 & -0.550633000 \\
1 & -4.684026000 & 2.035779000 & -0.812966000 \\
7 & -0.174112000 & 0.003333000 & 2.106641000 \\
7 & 2.032938000 & -0.856935000 & 2.364465000 \\
6 & -1.324372000 & 0.455268000 & 2.671777000 \\
1 & -2.136057000 & 0.702659000 & 2.003286000 \\
6 & -1.496817000 & 0.604713000 & 4.033323000 \\
1 & -2.456018000 & 0.937535000 & 4.421440000 \\
6 & -0.400529000 & 0.355726000 & 4.865961000 \\
1 & -0.466349000 & 0.520095000 & 5.939582000 \\
6 & 0.787602000 & -0.080902000 & 4.299436000 \\
1 & 1.659058000 & -0.238427000 & 4.924873000 \\
\hline & 0.869378000 & -0.293084000 & 2.906588000 \\
\hline & 2.799042000 & -1.697009000 & 3.305267000 \\
\hline & 2.093856000 & -2.274369000 & 3.904958000 \\
\hline & 3.421291000 & -2.390232000 & 2.736777000
\end{tabular}




$\begin{array}{llll}1 & 3.436316000 & -1.104871000 & 3.974410000 \\ 6 & 2.742298000 & -0.386540000 & 1.250140000 \\ 6 & 4.140183000 & -0.345605000 & 1.349629000 \\ 1 & 4.630218000 & -0.555862000 & 2.291486000\end{array}$

NEB \#3:

$\begin{array}{lrrr}24 & 0.032777000 & -0.005506000 & -0.005640000 \\ 7 & 0.135490000 & -2.085428000 & -0.357432000 \\ 6 & 1.305511000 & -2.666196000 & -0.732429000 \\ 1 & 2.187828000 & -2.049313000 & -0.732143000 \\ 7 & -2.149429000 & -2.385790000 & 0.249844000 \\ 6 & 1.435747000 & -3.997865000 & -1.076402000 \\ 1 & 2.414561000 & -4.388019000 & -1.341970000 \\ 7 & -2.068771000 & -0.004481000 & -0.102766000 \\ 6 & 0.285378000 & -4.790660000 & -1.093103000 \\ 1 & 0.322268000 & -5.830309000 & -1.410400000 \\ 7 & -0.001115000 & 0.193761000 & -2.091156000 \\ 6 & -0.915148000 & -4.220218000 & -0.702784000 \\ 1 & -1.827863000 & -4.804478000 & -0.721321000 \\ 7 & 2.378510000 & 0.142651000 & -2.330466000 \\ 6 & -0.959106000 & -2.872647000 & -0.293795000 \\ 7 & 2.138992000 & -0.005112000 & 0.101184000 \\ 6 & -2.986583000 & -3.391910000 & 0.935268000 \\ 1 & -3.613383000 & -3.968290000 & 0.244338000 \\ 1 & -2.329315000 & -4.074550000 & 1.477809000 \\ 1 & -3.627511000 & -2.879080000 & 1.655820000 \\ 6 & -2.773118000 & -1.177861000 & -0.062892000 \\ 6 & -4.164682000 & -1.206363000 & -0.216270000 \\ 1 & -4.682137000 & -2.155200000 & -0.284233000 \\ 6 & -4.873967000 & -0.016106000 & -0.248726000 \\ 1 & -5.960421000 & -0.020644000 & -0.306431000 \\ 6 & -1.184925000 & 0.249987000 & -2.757175000 \\ 1 & -2.041021000 & 0.591122000 & -2.206878000 \\ 6 & -1.353440000 & -0.100707000 & -4.081016000\end{array}$




\begin{tabular}{lrrr}
1 & -2.331209000 & 0.007273000 & -4.542977000 \\
6 & -0.255023000 & -0.638518000 & -4.757306000 \\
1 & -0.350063000 & -1.029195000 & -5.767712000 \\
6 & 0.971904000 & -0.649031000 & -4.115307000 \\
1 & 1.844185000 & -1.047514000 & -4.620132000 \\
6 & 1.096441000 & -0.128664000 & -2.808067000 \\
6 & 3.344519000 & 0.478749000 & -3.408043000 \\
1 & 2.789806000 & 0.865440000 & -4.260960000 \\
1 & 4.016515000 & 1.262513000 & -3.056440000 \\
1 & 3.928082000 & -0.394832000 & -3.723960000 \\
6 & 2.908883000 & 0.038710000 & -1.045866000 \\
6 & 4.309688000 & -0.050651000 & -0.990339000 \\
1 & 4.896700000 & -0.118846000 & -1.891986000 \\
6 & 4.954721000 & -0.048693000 & 0.228534000 \\
1 & 6.041245000 & -0.065245000 & 0.279117000 \\
7 & 0.096252000 & 2.074982000 & 0.347389000 \\
6 & 1.228695000 & 2.657434000 & 0.822071000 \\
1 & 2.115973000 & 2.048617000 & 0.863072000 \\
7 & -2.133003000 & 2.378402000 & -0.443990000 \\
6 & 1.314835000 & 3.979285000 & 1.215354000 \\
1 & 2.266239000 & 4.372773000 & 1.562525000 \\
6 & 0.155076000 & 4.757409000 & 1.173716000 \\
1 & 0.153984000 & 5.786140000 & 1.526397000 \\
6 & -1.003175000 & 4.188235000 & 0.670512000 \\
1 & -1.920177000 & 4.764300000 & 0.630353000 \\
6 & -0.997830000 & 2.854845000 & 0.216535000 \\
1 & -2.903506000 & 3.399946000 & -1.183470000 \\
\hline 1 & -3.594910000 & 3.959726000 & -0.542053000 \\
\hline 6 & -2.198322000 & 4.095465000 & -1.643436000 \\
\hline 1.471507000 & 2.906550000 & -1.975528000 \\
\hline 1.775128000 & 1.163465000 & -0.213015000 \\
\hline 1 & -4.704854000 & 2.124347000 & -0.192382000 \\
\hline 1 & -0.201455000 & 2.070794000
\end{tabular}




$\begin{array}{rrrr}7 & 2.146913000 & -0.122357000 & 2.543710000 \\ 6 & -1.439643000 & -0.256843000 & 2.622362000 \\ 1 & -2.235494000 & -0.622442000 & 2.001303000 \\ 6 & -1.738323000 & 0.126107000 & 3.914002000 \\ 1 & -2.754012000 & 0.015546000 & 4.283791000 \\ 6 & -0.717160000 & 0.701255000 & 4.675566000 \\ 1 & -0.913989000 & 1.120456000 & 5.659573000 \\ 6 & 0.565704000 & 0.710232000 & 4.154318000 \\ 1 & 1.381096000 & 1.134107000 & 4.728547000 \\ 6 & 0.822150000 & 0.151098000 & 2.882779000 \\ 6 & 3.002328000 & -0.420596000 & 3.721330000 \\ 1 & 2.365143000 & -0.755640000 & 4.537337000 \\ 1 & 3.685678000 & -1.233411000 & 3.474091000 \\ 1 & 3.572076000 & 0.459286000 & 4.044413000 \\ 6 & 2.798724000 & -0.064632000 & 1.314039000 \\ 6 & 4.202375000 & -0.024263000 & 1.383969000 \\ 1 & 4.709761000 & 0.029592000 & 2.333512000\end{array}$

NEB \#4:

$\begin{array}{lrrr}24 & 0.039588000 & 0.004986000 & -0.005317000 \\ 7 & 0.145396000 & -2.086943000 & -0.310670000 \\ 6 & 1.347273000 & -2.692151000 & -0.503749000 \\ 1 & 2.226333000 & -2.121150000 & -0.263895000 \\ 7 & -2.196971000 & -2.405408000 & 0.025278000 \\ 6 & 1.501279000 & -3.996728000 & -0.932113000 \\ 1 & 2.501098000 & -4.403409000 & -1.059677000 \\ 7 & -2.099240000 & 0.004037000 & -0.110648000 \\ 6 & 0.351506000 & -4.743258000 & -1.199531000 \\ 1 & 0.414381000 & -5.756163000 & -1.589667000 \\ 7 & 0.115096000 & 0.309567000 & -2.072088000 \\ 6 & -0.882105000 & -4.170100000 & -0.934208000 \\ 1 & -1.795617000 & -4.729793000 & -1.103956000 \\ 7 & 2.329711000 & -0.515862000 & -2.272898000 \\ 6 & -0.959336000 & -2.853190000 & -0.442011000\end{array}$




\begin{tabular}{|c|c|c|c|}
\hline & 2.102298000 & 0.005306000 & 0.092148000 \\
\hline & -3.044638000 & -3.458567000 & 0.627803000 \\
\hline & -3.651489000 & -3.996080000 & -0.109119000 \\
\hline & -2.395853000 & -4.169113000 & 1.143804000 \\
\hline & -3.705220000 & -2.996259000 & 1.364806000 \\
\hline & -2.805439000 & -1.169105000 & -0.188252000 \\
\hline & -4.195918000 & -1.192068000 & -0.356079000 \\
\hline & -4.704029000 & -2.135058000 & -0.513238000 \\
\hline & -4.914944000 & -0.010935000 & -0.288513000 \\
\hline & -6.000350000 & -0.016581000 & -0.360625000 \\
\hline & -1.015069000 & 0.751533000 & -2.684921000 \\
\hline & -1.746063000 & 1.224529000 & -2.056212000 \\
\hline & -1.264411000 & 0.622189000 & -4.034173000 \\
\hline & -2.209620000 & 0.965280000 & -4.444986000 \\
\hline & -0.269125000 & 0.039952000 & -4.825947000 \\
\hline & -0.414481000 & -0.110008000 & -5.893563000 \\
\hline & 0.933241000 & -0.315792000 & -4.240358000 \\
\hline & 1.729615000 & -0.698610000 & -4.863435000 \\
\hline & 1.115030000 & -0.165505000 & -2.844991000 \\
\hline & 3.273933000 & -1.225352000 & -3.160893000 \\
\hline & 2.722706000 & -1.955737000 & -3.750368000 \\
\hline & 3.797280000 & -0.532925000 & -3.830739000 \\
\hline & 4.001137000 & -1.761943000 & -2.555775000 \\
\hline & 2.861304000 & -0.099093000 & -1.047823000 \\
\hline & 4.253879000 & 0.050756000 & -1.000927000 \\
\hline & 4.821662000 & 0.132818000 & -1.918801000 \\
\hline & 4.900308000 & -0.003222000 & 0.223453000 \\
\hline & 5.987079000 & -0.007941000 & 0.274910000 \\
\hline & 0.098298000 & 2.093747000 & 0.317434000 \\
\hline & 1.273741000 & 2.700965000 & 0.627988000 \\
\hline & 2.174606000 & 2.142687000 & 0.441428000 \\
\hline & -2.205340000 & 2.413459000 & -0.228325000 \\
\hline & 1.376828000 & 3.993149000 & 1.107848000 \\
\hline & 2.357726000 & 4.406542000 & 132664400 \\
\hline
\end{tabular}




\begin{tabular}{lrrr}
6 & 0.199687000 & 4.718210000 & 1.308298000 \\
1 & 0.217645000 & 5.717978000 & 1.735256000 \\
6 & -1.001194000 & 4.144141000 & 0.921558000 \\
1 & -1.931858000 & 4.690565000 & 1.029851000 \\
6 & -1.021409000 & 2.847475000 & 0.375108000 \\
6 & -2.986383000 & 3.485939000 & -0.886636000 \\
1 & -3.676867000 & 3.994837000 & -0.204288000 \\
1 & -2.286554000 & 4.216000000 & -1.298486000 \\
1 & -3.554309000 & 3.050766000 & -1.712383000 \\
6 & -2.822327000 & 1.169870000 & -0.114823000 \\
6 & -4.223983000 & 1.177205000 & -0.126563000 \\
1 & -4.758537000 & 2.113961000 & -0.033297000 \\
7 & -0.090508000 & -0.292323000 & 2.060919000 \\
7 & 2.106619000 & 0.515033000 & 2.469742000 \\
6 & -1.277153000 & -0.719152000 & 2.569571000 \\
1 & -1.964958000 & -1.166139000 & 1.876415000 \\
6 & -1.639041000 & -0.604658000 & 3.894574000 \\
1 & -2.621722000 & -0.936543000 & 4.216458000 \\
6 & -0.707286000 & -0.051946000 & 4.778925000 \\
1 & -0.941468000 & 0.082797000 & 5.832666000 \\
6 & 0.544254000 & 0.294769000 & 4.302018000 \\
1 & 1.289840000 & 0.657728000 & 4.995745000 \\
6 & 0.843631000 & 0.162335000 & 2.925115000 \\
6 & 2.967720000 & 1.221158000 & 3.442243000 \\
1 & 2.366219000 & 1.946089000 & 3.988388000 \\
1 & 3.436808000 & 0.526104000 & 4.148555000 \\
6 & 3.741150000 & 1.763938000 & 2.903368000 \\
6 & 2.751306000 & 0.103991000 & 1.297790000 \\
1 & 4.141579000 & -0.054082000 & 1.381409000 \\
\hline & 4.622021000 & -0.143498000 & 2.347450000
\end{tabular}

NEB \#5:

$24 \quad-0.000119000 \quad-0.017389000 \quad-0.007602000$

$\begin{array}{llll}7 & 0.061697000 & -2.109661000 & -0.237910000\end{array}$ 


\begin{tabular}{lrrr}
6 & 1.196488000 & -2.725336000 & -0.657547000 \\
1 & 2.061873000 & -2.107171000 & -0.808256000 \\
7 & -2.164787000 & -2.315602000 & 0.554159000 \\
6 & 1.304480000 & -4.086939000 & -0.866785000 \\
1 & 2.253815000 & -4.505288000 & -1.190570000 \\
7 & -2.097207000 & -0.006112000 & -0.105421000 \\
6 & 0.172356000 & -4.881134000 & -0.663060000 \\
1 & 0.192790000 & -5.951294000 & -0.856575000 \\
7 & 0.018339000 & 0.207549000 & -2.104004000 \\
6 & -0.990207000 & -4.274337000 & -0.216269000 \\
1 & -1.890982000 & -4.857796000 & -0.061123000 \\
7 & 2.342853000 & -0.293136000 & -2.286015000 \\
6 & -1.014141000 & -2.885395000 & 0.011778000 \\
7 & 2.131704000 & -0.027686000 & 0.095437000 \\
6 & -2.971947000 & -3.189263000 & 1.425447000 \\
1 & -3.613977000 & -3.880497000 & 0.866328000 \\
1 & -2.293081000 & -3.762267000 & 2.062235000 \\
1 & -3.599225000 & -2.562712000 & 2.063753000 \\
6 & -2.797348000 & -1.171373000 & 0.064567000 \\
6 & -4.179089000 & -1.239431000 & -0.124033000 \\
1 & -4.683182000 & -2.197014000 & -0.070472000 \\
6 & -4.895865000 & -0.071653000 & -0.342814000 \\
1 & -5.978933000 & -0.096915000 & -0.442886000 \\
6 & -1.125751000 & 0.479556000 & -2.782368000 \\
1 & -2.053357000 & 0.252225000 & -2.285720000 \\
6 & -1.162508000 & 0.963476000 & -4.077301000 \\
1 & -2.122177000 & 1.151485000 & -4.552320000 \\
6 & 0.051046000 & 1.210477000 & -4.724639000 \\
1 & 0.081984000 & 1.652028000 & -5.718190000 \\
6 & 1.224440000 & 0.844544000 & -4.082285000 \\
\hline 1 & 2.185332000 & 0.977240000 & -4.567998000 \\
\hline 6 & 1.177282000 & 0.290087000 & -2.791634000 \\
\hline & 3.175086000 & -0.983707000 & -3.294731000 \\
\hline & -867204000 & -0.310805000 & -3.814617000
\end{tabular}




\begin{tabular}{lrrr}
1 & 2.510873000 & -1.438260000 & -4.033104000 \\
1 & 3.737331000 & -1.779792000 & -2.799192000 \\
6 & 2.907515000 & -0.083986000 & -1.034579000 \\
6 & 4.306395000 & -0.032536000 & -0.984681000 \\
1 & 4.875551000 & 0.002741000 & -1.904558000 \\
6 & 4.950673000 & -0.040311000 & 0.239927000 \\
1 & 6.036623000 & -0.043916000 & 0.297207000 \\
7 & 0.029803000 & 2.072859000 & 0.208708000 \\
6 & 1.152572000 & 2.680331000 & 0.671304000 \\
1 & 2.018966000 & 2.060017000 & 0.808462000 \\
7 & -2.164636000 & 2.323856000 & -0.690217000 \\
6 & 1.252581000 & 4.033964000 & 0.929190000 \\
1 & 2.195123000 & 4.445154000 & 1.280890000 \\
6 & 0.119210000 & 4.828342000 & 0.736696000 \\
1 & 0.129278000 & 5.891641000 & 0.966404000 \\
6 & -1.028622000 & 4.232014000 & 0.240275000 \\
1 & -1.925243000 & 4.820269000 & 0.082392000 \\
6 & -1.040751000 & 2.853636000 & -0.052147000 \\
6 & -2.902491000 & 3.259135000 & -1.561517000 \\
1 & -3.611651000 & 3.884795000 & -1.007638000 \\
1 & -2.179645000 & 3.898196000 & -2.071336000 \\
1 & -3.447687000 & 2.687931000 & -2.315581000 \\
6 & -2.807754000 & 1.133407000 & -0.369423000 \\
6 & -4.208750000 & 1.128121000 & -0.425243000 \\
1 & -4.746234000 & 2.060018000 & -0.545010000 \\
7 & -0.193585000 & -0.216069000 & 2.085343000 \\
7 & 2.102985000 & 0.280811000 & 2.480786000 \\
6 & -1.403117000 & -0.450626000 & 2.655998000 \\
1 & -2.271765000 & -0.244183000 & 2.056169000 \\
6 & -1.575716000 & -0.874178000 & 3.961330000 \\
1 & -2.579803000 & -1.036310000 & 4.345965000 \\
6 & -0.437254000 & -1.095691000 & 4.739900000 \\
\hline 1 & -0.512119000 & -1.491689000 & 5.750195000 \\
\hline & 0.799364000 & -0.767346000 & 4.203933000
\end{tabular}




$\begin{array}{lrrr}1 & 1.705778000 & -0.882347000 & 4.789351000 \\ 6 & 0.888666000 & -0.273855000 & 2.890540000 \\ 6 & 2.829071000 & 1.027739000 & 3.529799000 \\ 1 & 3.462944000 & 0.387482000 & 4.154167000 \\ 1 & 2.093763000 & 1.518678000 & 4.171418000 \\ 1 & 3.440566000 & 1.797583000 & 3.051070000 \\ 6 & 2.787941000 & 0.031838000 & 1.298294000 \\ 6 & 4.183524000 & -0.038055000 & 1.391985000 \\ 1 & 4.654842000 & -0.070162000 & 2.365970000\end{array}$

NEB \#6:

$\begin{array}{lrrr}24 & -0.034485000 & -0.014860000 & 0.027437000 \\ 7 & -0.030470000 & -2.076273000 & -0.306279000 \\ 6 & 1.054003000 & -2.660895000 & -0.874154000 \\ 1 & 1.711690000 & -2.011383000 & -1.432825000 \\ 7 & -2.162279000 & -2.285072000 & 0.624939000 \\ 6 & 1.328926000 & -4.008253000 & -0.762258000 \\ 1 & 2.215386000 & -4.420241000 & -1.235629000 \\ 7 & -2.107239000 & 0.016850000 & -0.090977000 \\ 6 & 0.447255000 & -4.799144000 & -0.010814000 \\ 1 & 0.647304000 & -5.857384000 & 0.142220000 \\ 7 & -0.003321000 & 0.242100000 & -2.085777000 \\ 6 & -0.710058000 & -4.233839000 & 0.501273000 \\ 1 & -1.434400000 & -4.850319000 & 1.020847000 \\ 7 & 2.362806000 & -0.001233000 & -2.289062000 \\ 6 & -0.958476000 & -2.862879000 & 0.280645000 \\ 7 & 2.111461000 & -0.053096000 & 0.117375000 \\ 6 & -3.087829000 & -3.065443000 & 1.461422000 \\ 1 & -3.543600000 & -3.903162000 & 0.919277000 \\ 1 & -2.542919000 & -3.449462000 & 2.327817000 \\ 1 & -3.873874000 & -2.400356000 & 1.820938000 \\ 6 & -2.736082000 & -1.204093000 & -0.079774000 \\ 6 & -3.998021000 & -1.391374000 & -0.624243000 \\ 1 & -4.429121000 & -2.385799000 & -0.667511000\end{array}$




\begin{tabular}{|c|c|c|c|}
\hline & -4.691003000 & -0.280318000 & -1.101705000 \\
\hline & -5.664339000 & -0.394855000 & -1.570942000 \\
\hline & -1.162061000 & 0.369789000 & -2.782808000 \\
\hline & -2.055667000 & -0.011674000 & -2.320430000 \\
\hline & -1.247967000 & 0.904030000 & -4.053888000 \\
\hline & -2.214407000 & 0.962676000 & -4.546164000 \\
\hline & -0.075811000 & 1.373483000 & -4.651101000 \\
\hline & -0.093451000 & 1.867005000 & -5.619483000 \\
\hline & 1.126918000 & 1.150707000 & -3.998422000 \\
\hline & 2.063610000 & 1.448509000 & -4.455794000 \\
\hline & 1.143772000 & 0.508212000 & -2.746194000 \\
\hline & 3.241093000 & -0.504410000 & -3.373285000 \\
\hline & 3.832803000 & -1.337398000 & -2.987878000 \\
\hline & 2.610056000 & -0.877587000 & -4.182059000 \\
\hline & 3.913172000 & 0.266331000 & -3.766403000 \\
\hline & 2.897331000 & 0.010093000 & -1.005323000 \\
\hline & 4.299331000 & 0.016555000 & -0.932395000 \\
\hline & 4.886369000 & 0.172173000 & -1.826880000 \\
\hline & 4.925893000 & -0.193807000 & 1000 \\
\hline & 6.009901000 & -0.250909000 & 0.343670000 \\
\hline & -0.034797000 & 2.047473000 & 0.264276000 \\
\hline & 1.128116000 & 2.628182000 & 0.660139000 \\
\hline & 1.822803000 & 1.993392000 & 1.185739000 \\
\hline & -2.319085000 & 2.409630000 & -0.362130000 \\
\hline & 1.447715000 & 3.949798000 & 0.426395000 \\
\hline & 2.394766000 & 4.346910000 & 0.778176000 \\
\hline & 0.543715000 & 4.714255000 & -0.318556000 \\
\hline & 0.786269000 & 5.728400000 & -0.627840000 \\
\hline 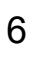 & -0.685980000 & 4.163712000 & -0.641750000 \\
\hline & -1.409974000 & 4.752333000 & -1.191714000 \\
\hline C & -0.997755000 & 2.840512000 & -0.256595000 \\
\hline & -3.332435000 & 3.491308000 & -0.316374000 \\
\hline & -2.915909000 & 4.331470000 & 0.237755000 \\
\hline & -3.631371000 & 3.824176000 & -1.316128000 \\
\hline
\end{tabular}




$\begin{array}{lrrr}1 & -4.202993000 & 3.134673000 & 0.234664000 \\ 6 & -2.823010000 & 1.118062000 & -0.457815000 \\ 6 & -4.131179000 & 0.974951000 & -0.969225000 \\ 1 & -4.670780000 & 1.839739000 & -1.326336000 \\ 7 & -0.234891000 & -0.258962000 & 2.103213000 \\ 7 & 2.091018000 & 0.032568000 & 2.536534000 \\ 6 & -1.470789000 & -0.398613000 & 2.650700000 \\ 1 & -2.306233000 & -0.121483000 & 2.030580000 \\ 6 & -1.697748000 & -0.827949000 & 3.944301000 \\ 1 & -2.717274000 & -0.912037000 & 4.309716000 \\ 6 & -0.594130000 & -1.165408000 & 4.730702000 \\ 1 & -0.717591000 & -1.575777000 & 5.730037000 \\ 6 & 0.673816000 & -0.940520000 & 4.217477000 \\ 1 & 1.553905000 & -1.157392000 & 4.811586000 \\ 6 & 0.828760000 & -0.425881000 & 2.916734000 \\ 6 & 2.891032000 & 0.602657000 & 3.644766000 \\ 1 & 3.571104000 & 1.352268000 & 3.233998000 \\ 1 & 2.210312000 & 1.097686000 & 4.340491000 \\ 1 & 3.472357000 & -0.152640000 & 4.185496000 \\ 6 & 2.757328000 & -0.150880000 & 1.325415000 \\ 6 & 4.144763000 & -0.313897000 & 1.417105000 \\ 1 & 4.603945000 & -0.495710000 & 2.379661000\end{array}$

NEB \#7:

$\begin{array}{llll}24 & -0.019576000 & -0.044455000 & -0.060631000 \\ 7 & 0.000444000 & -2.123900000 & -0.320824000 \\ 6 & 1.202565000 & -2.744778000 & -0.465349000 \\ 1 & 1.959945000 & -2.198978000 & -0.998767000 \\ 7 & -2.340120000 & -2.471877000 & -0.075810000 \\ 6 & 1.482059000 & -4.010071000 & 0.005511000 \\ 1 & 2.457566000 & -4.451544000 & -0.177497000 \\ 7 & -2.113883000 & -0.056896000 & -0.131269000 \\ 6 & 0.494985000 & -4.648006000 & 0.766220000 \\ 1 & 0.692183000 & -5.592409000 & 1.268470000\end{array}$




\begin{tabular}{lrrr}
7 & 0.037554000 & 0.327001000 & -2.130050000 \\
6 & -0.762719000 & -4.072764000 & 0.842368000 \\
1 & -1.545862000 & -4.566472000 & 1.404895000 \\
7 & 2.305014000 & -0.398269000 & -2.315206000 \\
6 & -1.026150000 & -2.859041000 & 0.165343000 \\
7 & 2.082449000 & -0.089418000 & 0.065443000 \\
6 & -3.328663000 & -3.575026000 & -0.077585000 \\
1 & -2.811594000 & -4.525147000 & -0.015076000 \\
1 & -4.024969000 & -3.476801000 & 0.760754000 \\
1 & -3.878128000 & -3.594203000 & -1.016829000 \\
6 & -2.836226000 & -1.203085000 & -0.375541000 \\
6 & -4.172547000 & -1.126485000 & -0.810586000 \\
1 & -4.738891000 & -2.015784000 & -1.030907000 \\
6 & -4.789132000 & 0.100360000 & -0.954287000 \\
1 & -5.805938000 & 0.158447000 & -1.334288000 \\
6 & -1.072423000 & 0.793170000 & -2.757701000 \\
1 & -1.986787000 & 0.826449000 & -2.189177000 \\
6 & -1.100990000 & 1.203689000 & -4.076272000 \\
1 & -2.037057000 & 1.542068000 & -4.511454000 \\
6 & 0.096909000 & 1.192412000 & -4.794825000 \\
1 & 0.143879000 & 1.560945000 & -5.816676000 \\
6 & 1.236189000 & 0.706208000 & -4.174591000 \\
1 & 2.181275000 & 0.702328000 & -4.703780000 \\
6 & 1.175579000 & 0.233236000 & -2.849074000 \\
6 & 3.176485000 & -1.058265000 & -3.308568000 \\
1 & 3.759885000 & -1.832321000 & -2.805368000 \\
1 & 2.542223000 & -1.533520000 & -4.059253000 \\
\hline 1 & 3.861167000 & -0.359906000 & -3.805344000 \\
\hline 6 & 2.866367000 & -0.161216000 & -1.057569000 \\
\hline 1 & 4.260237000 & -0.071480000 & -0.989971000 \\
\hline 1.846671000 & -0.041472000 & -1.899286000 \\
\hline & 0.147406000 & 2.054845000 & 0.097376000
\end{tabular}




\begin{tabular}{lrrr}
6 & 1.357708000 & 2.662122000 & -0.027287000 \\
1 & 2.233261000 & 2.038367000 & 0.020356000 \\
7 & -2.209716000 & 2.315444000 & 0.367429000 \\
6 & 1.528816000 & 4.018349000 & -0.219233000 \\
1 & 2.534046000 & 4.425088000 & -0.285812000 \\
6 & 0.388819000 & 4.811795000 & -0.371030000 \\
1 & 0.465525000 & 5.869578000 & -0.612818000 \\
6 & -0.852890000 & 4.215449000 & -0.229931000 \\
1 & -1.755015000 & 4.799894000 & -0.369071000 \\
6 & -0.951885000 & 2.838625000 & 0.062737000 \\
6 & -3.166973000 & 3.293772000 & 0.926995000 \\
1 & -2.622662000 & 3.957827000 & 1.601521000 \\
1 & -3.661383000 & 3.898050000 & 0.156114000 \\
1 & -3.924658000 & 2.755977000 & 1.499767000 \\
6 & -2.787671000 & 1.140295000 & -0.131088000 \\
6 & -4.106245000 & 1.246193000 & -0.582469000 \\
1 & -4.584062000 & 2.213404000 & -0.662606000 \\
7 & -0.239768000 & -0.366738000 & 2.018168000 \\
7 & 1.990907000 & 0.356615000 & 2.430787000 \\
6 & -1.424589000 & -0.775440000 & 2.546036000 \\
1 & -2.273362000 & -0.800400000 & 1.883998000 \\
6 & -1.603635000 & -1.122157000 & 3.871995000 \\
1 & -2.589004000 & -1.419995000 & 4.219944000 \\
6 & -0.491202000 & -1.101470000 & 4.717053000 \\
1 & -0.565003000 & -1.423068000 & 5.753551000 \\
6 & 0.717932000 & -0.661537000 & 4.203333000 \\
1 & 1.601331000 & -0.637589000 & 4.830772000 \\
6 & 0.809228000 & -0.251937000 & 2.858940000 \\
6 & 2.706142000 & 1.131206000 & 3.465806000 \\
1 & 3.322695000 & 1.887195000 & 2.974562000 \\
\hline & 1.964882000 & 1.637743000 & 4.088261000 \\
\hline & 3.343610000 & 0.505511000 & 4.101629000 \\
\hline & 2.706596000 & 0.054318000 & 1.275088000 \\
\hline & 4.102884000 & 0.005847000 & 1.390565000
\end{tabular}


NEB \#8:

$\begin{array}{lrrr}24 & 0.003573000 & -0.016832000 & -0.027468000 \\ 7 & 0.063272000 & -2.125565000 & -0.069508000 \\ 6 & 1.183687000 & -2.751683000 & 0.374933000 \\ 1 & 2.039587000 & -2.130759000 & 0.585298000 \\ 7 & -2.164118000 & -2.295173000 & -0.925016000 \\ 6 & 1.276337000 & -4.114269000 & 0.572484000 \\ 1 & 2.218265000 & -4.550655000 & 0.893796000 \\ 7 & -2.102266000 & -0.021340000 & -0.100981000 \\ 6 & 0.121289000 & -4.878614000 & 0.390983000 \\ 1 & 0.119829000 & -5.944841000 & 0.604510000 \\ 7 & 0.094779000 & 0.230039000 & -2.109024000 \\ 6 & -1.034433000 & -4.250372000 & -0.044957000 \\ 1 & -1.944671000 & -4.825021000 & -0.157444000 \\ 7 & 2.222523000 & -0.827568000 & -2.171038000 \\ 6 & -1.032499000 & -2.867679000 & -0.325509000 \\ 7 & 2.087403000 & 0.014460000 & 0.079029000 \\ 6 & -2.961383000 & -3.242478000 & -1.732926000 \\ 1 & -2.281817000 & -3.947127000 & -2.213276000 \\ 1 & -3.685136000 & -3.796586000 & -1.121787000 \\ 1 & -3.491900000 & -2.692126000 & -2.510526000 \\ 6 & -2.800232000 & -1.103721000 & -0.565878000 \\ 6 & -4.197591000 & -1.052017000 & -0.702872000 \\ 1 & -4.756391000 & -1.927585000 & -1.001543000 \\ 6 & -4.868472000 & 0.128067000 & -0.440422000 \\ 1 & -5.943083000 & 0.188785000 & -0.590710000 \\ 6 & -0.925683000 & 0.863306000 & -2.742068000 \\ 1 & -1.746806000 & 1.206438000 & -2.126372000 \\ 6 & -0.951073000 & 1.076260000 & -4.106338000 \\ 1 & -1.802454000 & 1.575460000 & -4.561173000\end{array}$




\begin{tabular}{lrrr}
6 & 0.149434000 & 0.646742000 & -4.856568000 \\
1 & 0.192695000 & 0.823907000 & -5.928740000 \\
6 & 1.207188000 & 0.018950000 & -4.215778000 \\
1 & 2.081482000 & -0.277868000 & -4.782406000 \\
6 & 1.161589000 & -0.183256000 & -2.822218000 \\
6 & 3.033356000 & -1.724772000 & -3.014136000 \\
1 & 3.577530000 & -2.417889000 & -2.369588000 \\
1 & 2.360449000 & -2.300596000 & -3.653023000 \\
1 & 3.748753000 & -1.178750000 & -3.642037000 \\
6 & 2.838521000 & -0.353206000 & -1.002862000 \\
6 & 4.235828000 & -0.307976000 & -0.955666000 \\
1 & 4.821960000 & -0.531409000 & -1.838373000 \\
6 & 4.865129000 & 0.042790000 & 0.231475000 \\
1 & 5.950978000 & 0.052760000 & 0.292533000 \\
7 & 0.065736000 & 2.101774000 & -0.005374000 \\
6 & 1.175346000 & 2.734045000 & -0.467265000 \\
1 & 1.999684000 & 2.112484000 & -0.785925000 \\
7 & -2.138376000 & 2.198056000 & 0.867444000 \\
6 & 1.290614000 & 4.107717000 & -0.543196000 \\
1 & 2.215671000 & 4.553842000 & -0.899016000 \\
6 & 0.181579000 & 4.879826000 & -0.181866000 \\
1 & 0.204793000 & 5.963227000 & -0.273698000 \\
6 & -0.967164000 & 4.244532000 & 0.263853000 \\
1 & -1.849039000 & 4.828464000 & 0.498982000 \\
6 & -0.999984000 & 2.838327000 & 0.363778000 \\
6 & -2.988784000 & 3.027489000 & 1.741989000 \\
1 & -2.343904000 & 3.595649000 & 2.415446000 \\
1 & -3.619637000 & 3.725976000 & 1.177886000 \\
1 & -3.626536000 & 2.371407000 & 2.337187000 \\
\hline 6 & -2.787546000 & 1.114645000 & 0.244087000 \\
\hline 1 & -4.162627000 & 1.226478000 & 0.029200000 \\
\hline & -4.673983000 & 2.160218000 & 0.223415000 \\
\hline & 1.961044000 & 0.853797000 & 2.331537000
\end{tabular}




$\begin{array}{lrrr}6 & -1.183826000 & -0.913555000 & 2.590170000 \\ 1 & -1.933104000 & -1.275834000 & 1.899790000 \\ 6 & -1.351401000 & -1.107774000 & 3.946950000 \\ 1 & -2.236834000 & -1.617910000 & 4.316982000 \\ 6 & -0.347900000 & -0.643450000 & 4.804273000 \\ 1 & -0.420302000 & -0.801095000 & 5.878220000 \\ 6 & 0.760371000 & -0.003592000 & 4.268279000 \\ 1 & 1.563598000 & 0.319662000 & 4.919463000 \\ 6 & 0.858518000 & 0.180776000 & 2.874442000 \\ 6 & 2.652358000 & 1.778645000 & 3.245828000 \\ 1 & 3.239222000 & 2.483080000 & 2.653383000 \\ 1 & 1.901645000 & 2.337941000 & 3.808312000 \\ 1 & 3.315332000 & 1.257737000 & 3.948191000 \\ 6 & 2.707617000 & 0.399960000 & 1.233972000 \\ 6 & 4.102904000 & 0.383546000 & 1.339582000 \\ 1 & 4.583921000 & 0.622341000 & 2.279603000\end{array}$

NEB \#9:

$\begin{array}{lrrr}24 & -0.000063000 & 0.000898000 & -0.000217000 \\ 7 & -0.094015000 & -2.054296000 & -0.023984000 \\ 6 & 0.820932000 & -2.779434000 & 0.657817000 \\ 1 & 1.445687000 & -2.233707000 & 1.347168000 \\ 7 & -1.928109000 & -1.921579000 & -1.492264000 \\ 6 & 0.977984000 & -4.130034000 & 0.477428000 \\ 1 & 1.735575000 & -4.664290000 & 1.031131000 \\ 7 & -2.034245000 & -0.000423000 & -0.094029000 \\ 6 & 0.142935000 & -4.772783000 & -0.435243000 \\ 1 & 0.234961000 & -5.836238000 & -0.609585000 \\ 7 & 0.190601000 & 0.102451000 & -2.046433000 \\ 6 & -0.828492000 & -4.051921000 & -1.098178000 \\ 1 & -1.513479000 & -4.549922000 & -1.764480000 \\ 7 & 2.087367000 & -1.283409000 & -1.907801000 \\ 6 & -0.943953000 & -2.676885000 & -0.859438000 \\ 7 & 2.034258000 & 0.000820000 & 0.093942000\end{array}$




\begin{tabular}{|c|c|c|c|}
\hline & -2.513472000 & -2.477389000 & -2.720669000 \\
\hline & -1.708796000 & -2.879284000 & -3.330935000 \\
\hline & -3.245649000 & -3.260958000 & -2.522555000 \\
\hline & -2.990699000 & -1.669601000 & -3.267655000 \\
\hline & -2.679341000 & -0.948759000 & -0.816729000 \\
\hline & -4.064891000 & -0.962338000 & -0.906443000 \\
\hline & -4.568017000 & -1.732619000 & -1.467118000 \\
\hline & -4.788042000 & -0.004322000 & -0.218322000 \\
\hline & -5.868458000 & -0.005770000 & -0.267105000 \\
\hline & -0.723014000 & 0.781649000 & -2.775489000 \\
\hline & -1.406302000 & 1.406660000 & -2.222602000 \\
\hline & -0.808095000 & 0.674601000 & -4.140300000 \\
\hline & -1.567523000 & 1.222048000 & -4.678415000 \\
\hline & 0.101893000 & -0.156011000 & -4.792526000 \\
\hline & 0.068163000 & -0.270568000 & -5.867466000 \\
\hline & 1.071727000 & -0.812947000 & -4.06 \\
\hline & 1.812977000 & -1.414035000 & -4.564615000 \\
\hline & 1.109930000 & -0.652401000 & -2.673365000 \\
\hline & 2.757167000 & -2.448248000 & -2.503948000 \\
\hline & 3.220605000 & -3.020792000 & -1.706016000 \\
\hline & 2.002917000 & -3.068630000 & -2.981066000 \\
\hline & 3.515187000 & -2.170602000 & -3.237038000 \\
\hline & 2.757518000 & -0.634854000 & -0.860409000 \\
\hline & 4.144801000 & -0.662676000 & -0.808231000 \\
\hline & 4.709745000 & -1.152785000 & -1.583556000 \\
\hline & 4.787972000 & -0.002587000 & 0.223608000 \\
\hline & 5.868296000 & -0.003842000 & 0.274444000 \\
\hline & -0.098385000 & 2.056067000 & 0.014275000 \\
\hline & 0.875084000 & 2.781851000 & -0.579995000 \\
\hline & 1.561680000 & 2.236408000 & -1.207952000 \\
\hline & -2.060215000 & 1.921840000 & 1.306970000 \\
\hline & 1.013300000 & 4.132749000 & -0.386666000 \\
\hline & 1.818674000 & 4.667314000 & -0.867918000 \\
\hline & 0.095908000 & 4.775182000 & 0.443405000 \\
\hline
\end{tabular}




$\begin{array}{lrrr}1 & 0.170352000 & 5.838793000 & 0.624908000 \\ 6 & -0.932474000 & 4.053667000 & 1.013302000 \\ 1 & -1.677116000 & 4.551217000 & 1.612609000 \\ 6 & -1.023244000 & 2.678249000 & 0.766384000 \\ 6 & -2.756418000 & 2.477486000 & 2.476310000 \\ 1 & -2.011826000 & 2.883242000 & 3.156270000 \\ 1 & -3.470400000 & 3.258121000 & 2.211314000 \\ 1 & -3.278261000 & 1.668681000 & 2.979164000 \\ 6 & -2.744312000 & 0.946349000 & 0.567197000 \\ 6 & -4.132362000 & 0.955737000 & 0.531715000 \\ 1 & -4.685600000 & 1.725377000 & 1.043662000 \\ 7 & 0.000431000 & -0.100820000 & 2.054912000 \\ 7 & 1.901729000 & 1.285307000 & 2.091530000 \\ 6 & -0.976292000 & -0.780550000 & 2.696596000 \\ 1 & -1.605736000 & -1.405497000 & 2.082946000 \\ 6 & -1.186603000 & -0.673977000 & 4.047809000 \\ 1 & -1.992107000 & -1.221648000 & 4.513846000 \\ 6 & -0.340684000 & 0.156668000 & 4.781231000 \\ 1 & -0.472707000 & 0.270529000 & 5.848654000 \\ 6 & 0.691615000 & 0.814275000 & 4.145058000 \\ 1 & 1.383274000 & 1.415154000 & 4.712272000 \\ 6 & 0.857815000 & 0.654380000 & 2.763788000 \\ 6 & 2.514828000 & 2.449441000 & 2.747062000 \\ 1 & 3.051291000 & 3.021384000 & 1.995673000 \\ 1 & 1.720429000 & 3.071107000 & 3.151920000 \\ 1 & 3.201681000 & 2.170699000 & 3.546955000 \\ 6 & 2.666300000 & 0.634897000 & 1.111932000 \\ 6 & 4.052325000 & 0.659347000 & 1.190498000 \\ 1 & 4.543487000 & 1.148785000 & 2.015027000\end{array}$

$\left[\mathrm{Cr}(\mathrm{ddpd})\left(\mathrm{K}^{2} \mathrm{~N}-\mathrm{ddpd}\right)\right]^{3+}$ :
$24 \quad 10.575316000$
13.219758000
5.444876000
$\begin{array}{lll}7 & 9.220212000 & 14.762761000\end{array}$
5.390157000
6
9.283273000
15.709474000
6.356467000 


\begin{tabular}{lccc}
1 & 10.150087000 & 15.685090000 & 6.995260000 \\
7 & 8.176461000 & 13.847927000 & 3.481868000 \\
6 & 8.302071000 & 16.648586000 & 6.539339000 \\
1 & 8.392949000 & 17.371182000 & 7.335150000 \\
7 & 10.462683000 & 13.169813000 & 3.403808000 \\
6 & 7.205398000 & 16.632045000 & 5.680085000 \\
1 & 6.407240000 & 17.351928000 & 5.791786000 \\
7 & 12.048815000 & 14.581253000 & 5.458148000 \\
6 & 7.156265000 & 15.709211000 & 4.656661000 \\
1 & 6.338948000 & 15.720568000 & 3.956603000 \\
7 & 13.006406000 & 13.587617000 & 7.362994000 \\
6 & 8.196116000 & 14.785657000 & 4.515384000 \\
7 & 10.662239000 & 13.214466000 & 7.499392000 \\
6 & 6.874511000 & 13.588752000 & 2.838441000 \\
1 & 6.585524000 & 14.380065000 & 2.148012000 \\
1 & 6.124521000 & 13.493856000 & 3.617991000 \\
1 & 6.938883000 & 12.647745000 & 2.302495000 \\
6 & 9.322191000 & 13.509302000 & 2.745747000 \\
6 & 9.260582000 & 13.513674000 & 1.359953000 \\
1 & 8.355615000 & 13.807409000 & 0.857230000 \\
6 & 10.392226000 & 13.188544000 & 0.636273000 \\
1 & 10.364015000 & 13.193733000 & -0.443937000 \\
6 & 12.088153000 & 15.497462000 & 4.458418000 \\
1 & 11.186191000 & 15.619465000 & 3.883774000 \\
6 & 13.215683000 & 16.215393000 & 4.165872000 \\
1 & 13.206837000 & 16.921170000 & 3.350464000 \\
6 & 14.356459000 & 15.993509000 & 4.938185000 \\
1 & 15.273101000 & 16.525051000 & 4.726354000 \\
6 & 14.306116000 & 15.117285000 & 5.999437000 \\
1 & 15.164310000 & 14.987612000 & 6.635296000 \\
\hline 1 & 13.115502000 & 14.429016000 & 6.272061000 \\
\hline & 14.249115000 & 13.157131000 & 8.023011000 \\
\hline
\end{tabular}




\begin{tabular}{llll}
1 & 14.691056000 & 13.945184000 & 8.632460000 \\
6 & 11.826603000 & 13.500241000 & 8.124646000 \\
6 & 11.877589000 & 13.693169000 & 9.496360000 \\
1 & 12.810314000 & 13.932566000 & 9.978012000 \\
6 & 10.700580000 & 13.624996000 & 10.224853000 \\
1 & 10.718484000 & 13.804201000 & 11.290519000 \\
7 & 11.886052000 & 11.646787000 & 5.346574000 \\
6 & 11.943383000 & 10.738103000 & 6.348745000 \\
1 & 11.162092000 & 10.787138000 & 7.085504000 \\
7 & 12.764419000 & 12.553811000 & 3.354761000 \\
6 & 12.956274000 & 9.823745000 & 6.469374000 \\
1 & 12.960744000 & 9.133470000 & 7.298420000 \\
6 & 13.964130000 & 9.827998000 & 5.507002000 \\
1 & 14.782842000 & 9.124979000 & 5.563613000 \\
6 & 13.902166000 & 10.725262000 & 4.462388000 \\
1 & 14.653200000 & 10.711065000 & 3.691328000 \\
6 & 12.836740000 & 11.630271000 & 4.392884000 \\
6 & 14.019521000 & 12.855486000 & 2.645789000 \\
1 & 14.295945000 & 12.081518000 & 1.930607000 \\
1 & 14.807487000 & 12.963889000 & 3.385144000 \\
1 & 13.899161000 & 13.800306000 & 2.126328000 \\
6 & 11.573672000 & 12.856574000 & 2.685439000 \\
6 & 11.561146000 & 12.864331000 & 1.297222000 \\
1 & 12.442459000 & 12.586171000 & 0.745964000 \\
7 & 8.796380000 & 10.294477000 & 7.505101000 \\
6 & 8.411884000 & 12.625492000 & 7.525155000 \\
\hline 1 & 8.972676000 & 9.151339000 & 6.838390000 \\
\hline 1 & 9.100185000 & 8.261078000 & 7.440872000 \\
\hline 6 & 9.013496000 & 9.071229000 & 5.444998000 \\
\hline 1.279979000 & 12.309550000 & 4.880093000
\end{tabular}




$\begin{array}{llll}6 & 8.611536000 & 11.402789000 & 6.794056000 \\ 6 & 7.093843000 & 12.719608000 & 8.166048000 \\ 1 & 6.344597000 & 12.463533000 & 7.421857000 \\ 1 & 6.928875000 & 13.742152000 & 8.496018000 \\ 1 & 6.997735000 & 12.038272000 & 9.013741000 \\ 6 & 9.522676000 & 13.059206000 & 8.233240000 \\ 6 & 9.508013000 & 13.310528000 & 9.597654000 \\ 1 & 8.596922000 & 13.197415000 & 10.161198000\end{array}$




\section{References}

1 S. Otto, M. Grabolle, C. Förster, C. Kreitner, U. Resch-Genger and K. Heinze, Angew. Chem. Int. Ed., 2015, 54, 11572.

2 J. W. Emsley and L. Phillips, Prog. Nucl. Magn. Reson. Spectrosc., 1971, 7, 1.

3 F. Zinna, T. Bruhn, C. A. Guido, J. Ahrens, M. Bröring, L. Di Bari and G. Pescitelli, Chem. Eur. J., 2016, 22, 16089.

$4 \quad$ F. Zinna, L. Arrico and L. Di Bari, Chem. Commun., 2019, 55, 6607.

5 F. Neese, WIREs Comput. Mol. Sci., 2012, 2, 73.

$6 \quad$ A. D. Becke, J. Chem. Phys., 1993, 98, 5648.

7 C. Lee, W. Yang and R. G. Parr, Phys. Rev. B, 1988, 37, 785.

8 B. Miehlich, A. Savin, H. Stoll and H. Preuss, Chem. Phys. Lett., 1989, 157, 200.

9 F. Neese, F. Wennmohs, A. Hansen and U. Becker, Chem. Phys., 2009, 356, 98.

10 R. Izsák and F. Neese, J. Chem. Phys., 2011, 135, 144105.

11 D. A. Pantazis, X.-Y. Chen, C. R. Landis and F. Neese, J. Chem. Theory Comput., 2008, 4, 908.

12 S. Sinnecker, A. Rajendran, A. Klamt, M. Diedenhofen and F. Neese, J. Phys. Chem. A, 2006, 110, 2235.

13 S. Grimme, J. Antony, S. Ehrlich and H. Krieg, J. Chem. Phys., 2010, 132, 154104.

14 S. Grimme, S. Ehrlich and L. Goerigk, J. Comput. Chem., 2011, 32, 1456.

15 F. Weigend and R. Ahlrichs, Phys. Chem. Chem. Phys., 2005, 7, 3297.

16 F. Weigend, Phys. Chem. Chem. Phys., 2006, 8, 1057.

17 S. Smidstrup, A. Pedersen, K. Stokbro and H. Jónsson, J. Chem. Phys., 2014, 140, 214106.

18 J. Nocedal, Math. Comp., 1980, 35, 773.

19 S. Otto, J. P. Harris, K. Heinze and C. Reber, Angew. Chem. Int. Ed., 2018, 57, 11069.

20 J. Autschbach in Comprehensive Inorganic Chemistry II, 2nd ed. (Eds. J. Reedijk, K. Poeppelmeier), Elsevier, Amsterdam, 2013; pp. 407.

21 M. Srebro-Hooper and J. Autschbach, Annu. Rev. Phys. Chem., 2017, 68, 399.

22 G. Pescitelli and T. Bruhn, Chirality, 2016, 28, 466.

23 M. Enamullah, A. Uddin, G. Pescitelli, R. Berardozzi, G. Makhloufi, V. Vasylyeva, A. C. Chamayou and C. Janiak, Dalton Trans., 2014, 43, 3313.

24 G. Pescitelli, S. Lüdeke, A.-C. Chamayou, M. Marolt, V. Justus, M. Górecki, L. Arrico, L. Di Bari, M. A. Islam, I. Gruber, M. Enamullah and C. Janiak, Inorg. Chem., 2018, 57, 13397.

25 Gaussian 16 (Revision A.03): M. J. Frisch, G. W. Trucks, H. B. Schlegel, G. E. Scuseria, M. A. Robb, J. R. Cheeseman, G. Scalmani, V. Barone, G. A. Petersson, H. Nakatsuji, X. Li, M. Caricato, A. V. Marenich, J. Bloino, B. G. Janesko, R. Gomperts, B. Mennucci, H. P. Hratchian, J. V. Ortiz, A. F. Izmaylov, J. L. Sonnenberg, D. Williams-Young, F. Ding, F. Lipparini, F. Egidi, J. Goings, B. Peng, A. Petrone, T. Henderson, D. Ranasinghe, V. G. Zakrzewski, J. Gao, N. Rega, G. Zheng, W. Liang, M. Hada, M. Ehara, K. Toyota, R. Fukuda, J. Hasegawa, M. Ishida, T. Nakajima, Y. Honda, O. Kitao, H. Nakai, T. Vreven, K. Throssell, J. A. Montgomery, Jr., J. E. Peralta, F. Ogliaro, M. J. Bearpark, J. J. Heyd, E. N. Brothers, K. N. Kudin, V. N. Staroverov, T. A. Keith, R. Kobayashi, J. Normand, K. 
Raghavachari, A. P. Rendell, J. C. Burant, S. S. Iyengar, J. Tomasi, M. Cossi, J. M. Millam, M. Klene, C. Adamo, R. Cammi, J. W. Ochterski, R. L. Martin, K. Morokuma, O. Farkas, J. B. Foresman and D. J. Fox, Gaussian, Inc., Wallingford CT, 2016.

26 T. Bruhn, A. Schaumlöffel, Y. Hemberger and G. Bringmann, Chirality, 2013, 25, 243.

27 T. Bruhn, A. Schaumlöffel, Y. Hemberger and G. Pescitelli, SpecDis (version 1.71), Berlin, Germany, 2017; Web: https://specdis-software.jimdo.com (last access: August 11, 2019). 


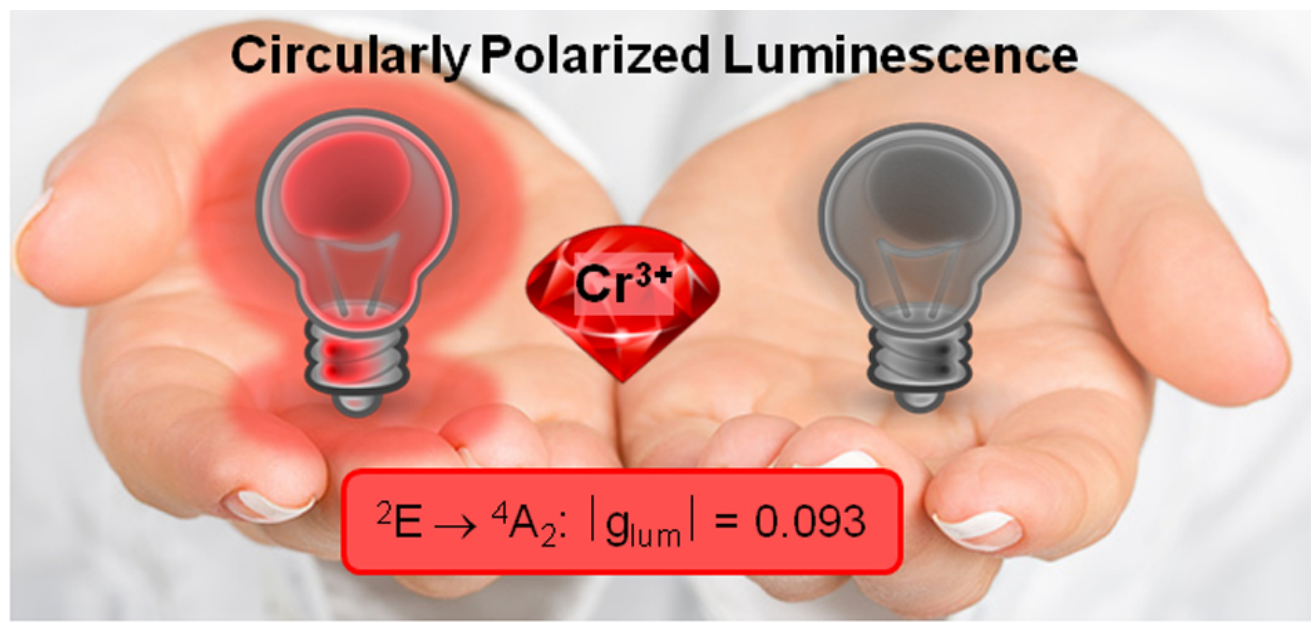

$80 \times 37 \mathrm{~mm}(300 \times 300$ DPI $)$ 